\title{
Ground-based remote sensing observation of the complex behaviour of the Marseille boundary layer during ESCOMPTE
}

\author{
H. Delbarre,*, P. Augustin ${ }^{\mathrm{a}}$, F. Saïd ${ }^{\mathrm{b}}$, B. Campistron ${ }^{\mathrm{b}}$, B. Bénech ${ }^{\mathrm{b}}$, \\ F. Lohou ${ }^{\mathrm{b}}$, V. Puygrenier ${ }^{\mathrm{b}}$, C. Moppert ${ }^{\mathrm{c}}$, F. Cousin ${ }^{\mathrm{c}}$, \\ P. Fréville ${ }^{\mathrm{a}}$, E. Fréjafon ${ }^{\mathrm{d}}$
}
${ }^{a}$ Laboratoire de Physico-Chimie de l'Atmosphère, UMR CNRS 8101, Université du Littoral-Côte d'Opale, 145, Avenue M. Schumann, 59140 Dunkerque, France
${ }^{\mathrm{b}}$ Laboratoire d'Aérologie, UMR 5560 CNRS/OMP/UPS, Centre de Recherches Atmosphériques, 65300 Campistrous, France
${ }^{\mathrm{c}}$ Laboratoire d'Aérologie, UMR 5560 CNRS/OMP/UPS, Observatoire Midi-Pyrénées, 14 av. E. Belin, 31400 Toulouse, France
dinstitut National de l'Environnement et des Risques Industriels, Parc Technologique ALATA, BP 2, 60550 Verneuil en Halatte, France

Ground-based remote sensing systems have been used during the ESCOMPTE campaign, to continuously characterize the boundary-layer behaviour through many atmospheric parameters (wind, extinction and ozone concentration distribution, reflectivity, turbulence). This analysis is focused on the comparison of the atmospheric stratification retrieved from a UV angular ozone lidar, an Ultra High Frequency wind profiler and a sodar, above the area of Marseille, on June 26th 2001 (Intensive Observation Period 2b). The atmospheric stratification is shown to be very complex including two superimposed sea breezes, with an important contribution of advection. The temporal and spatial evolution of the stratification observed by the UV lidar and by the UHF radar are in good agreement although the origin of the echoes of these systems is quite different. The complexity of the

* Corresponding author. Tel.: +33 3286582 65; fax: +33 328658244.
E-mail address: herve.delbarre@univ-littoral.fr (H. Delbarre). 
dynamic situation has only partially been retrieved by a non-hydrostatic mesoscale model used with a $3 \mathrm{~km}$ resolution.

Keywords: ESCOMPTE; Boundary layer; Sea breeze; Lidar; Wind profiler

\section{Introduction}

During June and July 2001, the regional ESCOMPTE program has completed many air pollution investigations, from the Marseille-Berre region, in order to validate air pollution models (Cros et al., 2004) and predict photochemical pollution episodes. During this campaign, a side project was also devoted to the characterisation of the Urban Boundary Layer (UBL) dynamics more specifically over the Marseille town (Mestayer et al., in press). Joined efforts gave the opportunity to deploy, over Marseille, several ground-based remote sensing instruments such as lidars, radars and sodars, for a quasicontinuous monitoring of the low troposphere during the four 3-day intensive observation periods with low wind and high insolation favourable to high ozone concentration episodes and sea breeze events. These measurements were also accompanied by several punctual radiosoundings and airborne measurements. The aim of this study is to analyse, mainly through the ground-based remote sensing instruments, the structure and the dynamics of the urban boundary layer on June 26th, corresponding to a high ozone level day at the end of a photochemically polluted Intensive Observation Period (IOP2b). The analysis of the atmospheric stratification will show that the dynamics of the atmosphere is complex and cannot be limited neither to a single urban boundary-layer dynamics nor to a single sea breeze dynamics. This work will also give the opportunity to highlight some interesting correlations between remote-sensed measurements such as clear air radar and ozone lidar data. Both measurements providing well-matched information with additional specificities that help for the understanding of the Atmospheric Boundary Layer (ABL) evolution.

The analysis will be compared to a simulation from the Mesoscale NonHydrostatic Chemistry (MesoNH-C) model (Cousin et al., 2004). Two-way grid nested simulations are performed with a $9 \mathrm{~km}$ resolution for the large domain between latitudes $40.8^{\circ} \mathrm{N}$ and $47^{\circ} \mathrm{N}$ and longitudes $1.06^{\circ} \mathrm{E}$ and $10.02^{\circ} \mathrm{E}$. The embedded ESCOMPTE small domain $(3 \mathrm{~km}$ resolution) centered on Marseille and Berre pond is located between latitudes $42.7^{\circ} \mathrm{N}$ and $44.3^{\circ} \mathrm{N}$ and longitudes $4.22^{\circ} \mathrm{E}$ and $6.42^{\circ} \mathrm{E}$. There are 54 vertical levels, 40 of which lie between the surface and $2500 \mathrm{~m}$ in the boundary layer. The simulation was started on June 21st at 0:00 UTC, at the beginning of IOP2a.

\section{Tools for analysis of the boundary-layer stratification and dynamics}

The location of the experimental set-up presented in the following is shown in Fig. 1. The sites were devoted to the Marseille UBL study and were situated either inside the town 


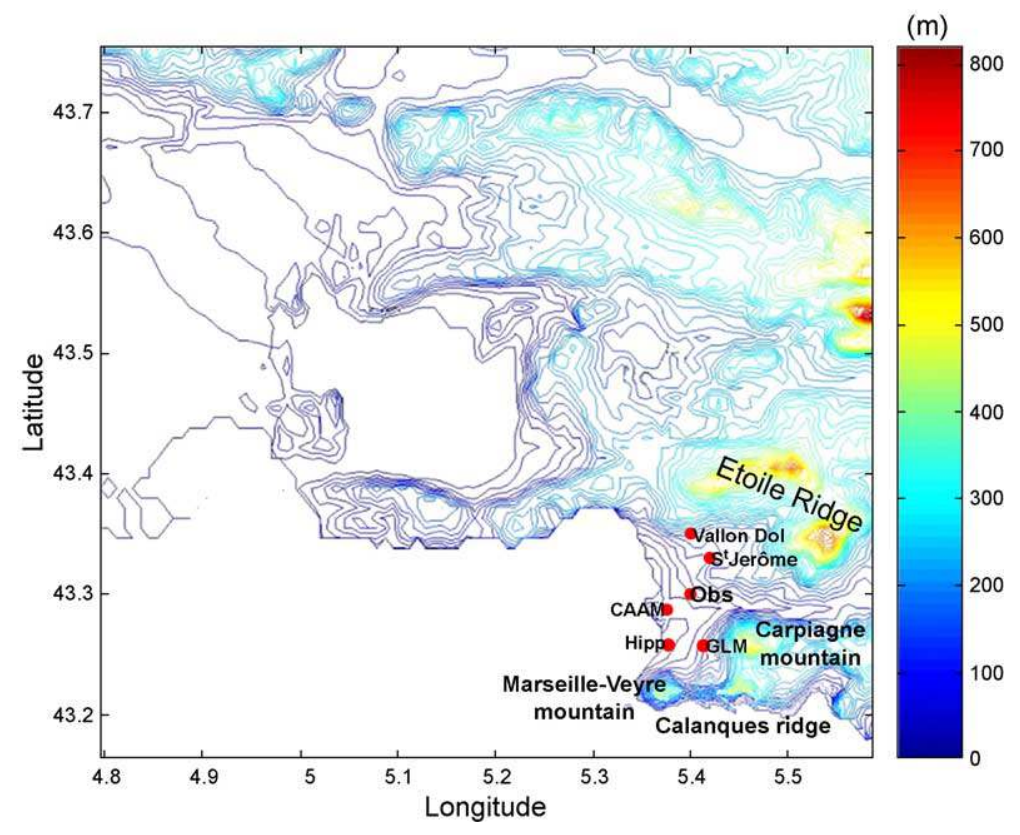

Fig. 1. Experimental area with the location of the ground stations listed below with their respective characteristics (altitude above sea-level/shortest distance to the shoreline): Observatoire (Obs): $60 \mathrm{~m} / 3 \mathrm{~km}$; St Jérôme: $130 \mathrm{~m} / 6$ km; Hippodrome (Hipp): 12 m/0.5 km; Groupement de Laboratoires de Marseille (GLM): $32 \mathrm{~m} / 3 \mathrm{~km}$; Cour d'Appel administrative de Marseille (CAAM): $13 \mathrm{~m} / 1.5 \mathrm{~km}$ and Vallon dol: $285 \mathrm{~m} / 5 \mathrm{~km}$.

or in the northern suburb. The city is bordered by the sea to the South and to the West and by topographical features to the South (Calanques ridge), South-East (Carpiagne Mountain) and North (Etoile ridge). A separation between the features to the SouthEast and North, is likely to induce a channel effect from the East.

\subsection{Remote-sensing experimental set}

An ultraviolet lidar, a Ultra High-Frequency (UHF) radar, a sodar operated simultaneously above the Marseille town and allowed a quasi-continuous remote monitoring of the boundary layer and low troposphere.

\subsubsection{UV lidar}

The UV angular lidar from the "Laboratoire de Physico-Chimie de l'Atmosphère" (Université du Littoral-Côte d'Opale, Dunkerque, France), is an ELIGHT 510M commercial instrument. This system has already been involved and tested in many previous air pollution campaigns (Kölsch et al., 1992; Kambezidis et al., 1998; Thomasson et al., 2002). The campaign was led in cooperation with the "Institut National de l'Environnement et des Risques Industriels" (Verneuil en Halatte. France). The lidar was located at Vallon Dol $\left(43.36^{\circ} \mathrm{N}, 5.4^{\circ} \mathrm{E}\right)$ North to Marseille, at a $285 \mathrm{~m}$ asl and about $5 \mathrm{~km}$ from the coast. This Differential Absorption Lidar (DIAL) allows the 
continuous measurement, in any direction, of $\mathrm{O}_{3}, \mathrm{SO}_{2}, \mathrm{NO}_{2}$, benzene and toluene, providing both concentration and extinction coefficient. The pollutant is selected by choosing the two reference and absorption wavelengths of a dual wavelengths laser. The primary laser is a flashlamp-pumped Ti:Sapphire pulsed infrared laser. The optical frequency of each pulse is doubled and tripled in nonlinear crystals to generate $50 \mathrm{~ns}$ ultraviolet pulses with a few $\mathrm{mJ}$ energy in the [250, $290 \mathrm{~nm}]$ wavelength range. During the ESCOMPTE experiment, this UV angular lidar measured the ozone concentration and the extinction distribution. The vertical angular scans consisted in measuring the spatial distribution of the ozone concentration along several consecutive beams with a $10^{\circ}$ angle resolution in vertical planes, to generate vertical maps of the ozone concentration and the extinction. The vertical scans were primarily performed in a vertical plane oriented close to the North-South line. Dual reference and absorption wavelengths for ozone concentration measurements were fixed respectively to 286.3 and $282.4 \mathrm{~nm}$ and the total extinction coefficient was determined by the $286.3 \mathrm{~nm}$ reference wavelength. Angular scans were obtained in a 30-min duration per scan, with a spatial resolution of $100 \mathrm{~m}$. The range of each measurement direction was from 200 to $2500 \mathrm{~m}$. The measurements were continuous during the four 3-day intensive observation periods (IOP) from June 15th, 2001 up to July 14th, 2001, except for unavoidable calibration procedures and optical realignments, whose duration was generally shorter than the atmospheric dynamics.

Through these continuous measurements of ozone concentration and extinction, this lidar provides useful information on the dynamics of the atmospheric boundary layer above Marseille.

\subsubsection{UHF wind-profiler}

Four UHF wind profilers were deployed over the ESCOMPTE domain in order to provide vertical profiles of the wind in the lower atmosphere with high temporal and spatial resolution in clear air and precipitating conditions. This UHF network was composed of several identical DEGREWIND PCL1300 instruments, manufactured by the French Etablissement Degreane.

For the present study, observations of the UHF profiler sited at the Observatoire (Fig. 1), downtown Marseille, are used only. This five-beam wind profiler owned and operated continuously during the campaign by the CNRM (Météo-France) has the following main characteristics: a $1280 \mathrm{MHz}$ transmitted frequency, a $4 \mathrm{~kW}$ peak power, a $20 \mathrm{kHz}$ pulse repetition frequency, a $150 \mathrm{~m}$ pulse width. In order to obtain the three components of the wind, the profiler sequentially uses five beams, one vertical and four oblique, with a one-way half-power aperture of $8.5^{\circ}$. The oblique beams, with an offzenith angle of $17^{\circ}$, are disposed every $90^{\circ}$ in azimuth. A real time spectral analysis applied for each beam gives the Doppler spectra at selected range gates from $75 \mathrm{~m}$ up to a height of about $3 \mathrm{~km}$, with a $75 \mathrm{~m}$ vertical resolution. The spectra, contaminated by noise and non-meteorological echoes, are carefully edited in order to select and extract the first three moments of the atmospheric peak: radar reflectivity, radial velocity, and spectral width. Data quality control and processing are performed through a consensus algorithm based on time (30 $\mathrm{min}$ ) and height continuity (three range gates) of the edited spectra. The zenith-pointing beam radial velocity provides air vertical velocity. 
Horizontal wind components are inferred from the measurements of the oblique and vertical beams under the assumption of horizontal wind local homogeneity. Finally vertical profiles of the three components of the wind, and for each beam spectral width and radar reflectivity, are obtained every $5 \mathrm{~min}$. More detailed technical description can be found in Jacoby-Koaly et al. (2002).

Assessment of the UHF profiler measurements was made during a 1-year validation campaign with the use of rawinsoundings, sodar and sonic anemometers (Dessens et al., 1997). On the other hand, the ability of UHF radar to detect rain of even weak intensity was used to compare with the droplet size distributions observed by a disdrometer at the ground level allowing the instruments reflectivity to be calibrated and to assess vertical velocity and spectral width retrieval (Campistron et al., 1997).

\subsubsection{Sodar}

The third remote-sensing device used here is the Doppler sodar-RASS manufactured by Metek Company and operated continuously at the Vallon Dol site. Measurements acquisition and treatment have been carried out by A. Mériaux (Alliance Technologies), H. J. Kirtzel (Metek company) in cooperation with J. M. Rosant (Laboratoire de Mécanique des Fluides (LMF), CNRS/Ecole Centrale de Nantes (ECN)). This acoustic sounding provided the horizontal components of the wind and spectral width from $320 \mathrm{~m}$ up to 750 $\mathrm{m}$ asl (depending of the atmospheric conditions) by a $25-\mathrm{m}$ vertical step and a $15-\mathrm{min}$ dwell-time.

\subsection{Approach of the low troposphere stratification through lidar and UHF radar measurements}

\subsubsection{Stratification information from lidar}

The received power from a distance $r$, greater than $r_{0}$ corresponding to the lidar onset distance for a maximum overlap of the receiver system by the laser beam, can be written according to the local backscattering coefficient $\beta(r, \lambda)$ and extinction coefficient $\alpha(r, \lambda)$ as follows:

$$
P\left(r>r_{0}, \lambda\right)=\frac{K P_{0}}{r^{2}} \beta(r, \lambda) \exp \left\{-2 \int_{0}^{r} \alpha\left(r^{\prime}, \lambda\right) \mathrm{d} r^{\prime}\right\}
$$

where $P_{0}$ is the transmitted power at a laser wavelength $\lambda$ and $K$ is the lidar system constant (VDI-DIN 4210, 1997). According to the DIAL technique, the gas concentration $C(r)$ (in mass per volume unit) of a specific pollutant with a molecular mass $M$, can be determined from the received power from two successive pulses with respective closed wavelengths $\lambda_{0}$ and $\lambda_{1}$. The gas concentration is recovered from the differential of the logarithm of the received powers ratio (2), the differential absorption cross-sections $\sigma\left(\lambda_{0}\right)$ and $\sigma\left(\lambda_{1}\right)$ must be known (Zanzottera, 1990):

$$
C(r)=\frac{M}{2\left(\sigma\left(\lambda_{1}\right)-\sigma\left(\lambda_{0}\right)\right)} \frac{\mathrm{d}}{\mathrm{d} r}\left[\ln \frac{P\left(r, \lambda_{0}\right)}{P\left(r, \lambda_{1}\right)}\right]
$$


This concentration computation relies on the assumption that the backscattering and extinction coefficients are identical for the very close wavelengths $\lambda_{0}$ and $\lambda_{1}$. Practically, this assumption leads to a concentration error stemming from Rayleigh and Mie scattering. In the following measurements, the ozone concentration has been corrected from the Rayleigh error, but the Mie error has been neglected. Indeed, this Mie correction has been discussed by Thomasson et al. (2002), who made a comparison between lidar ozone concentration measurements and spot analysers along the lidar optical beam, during an ozone episode over Paris, giving a $10 \mu \mathrm{g} / \mathrm{m}^{3}$ systematic error for a $0.54 \mathrm{~km}^{-1}$ extinction. Moreover, the ozone measurement precision has been proved to be better than $15 \%$ during an intercomparison campaign within the ESCOMPTE program (Frejafon et al., 2002).

The aerosols distribution extraction from lidar signals is less obvious because of the lack of well defined absorption spectra like gases. However, some information on stratification can be extracted from the backscattered lidar signals. It is convenient to linearize the exponential decrease of lidar signals according to the optical depth and avoid the inverse squared distance dependence by introducing a corrected backscattered signal $S(r, \lambda)$ :

$$
S(r, \lambda)=\ln \left[P(r, \lambda) r^{2}\right]
$$

The corrected backscattered signal $S(r, \lambda)$ decreases linearly when the lidar beam goes through an homogeneous layer. Fig. 2 (diagram a) displays an example of the corrected backscattered signal when the laser beam crosses over two consecutive homogeneous layers with different aerosols and/or gas loadings. The transition between the layers is recognized on the signal $S(r, \lambda)$ by an intensity step due to the abrupt change of the backscattering coefficient, and alternatively, by a slope variation relative to

(a)

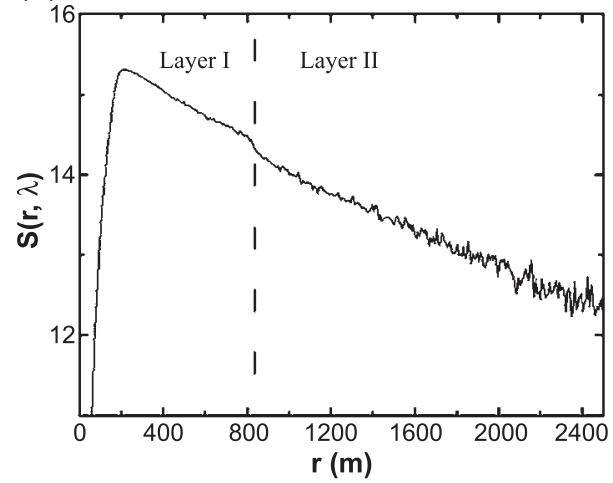

(b)

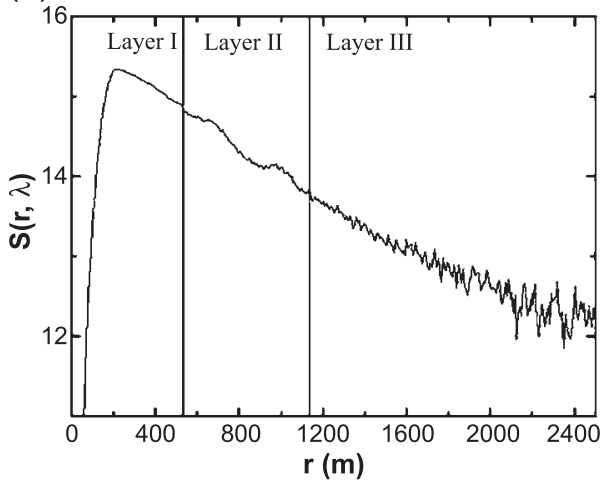

Fig. 2. Corrected backscattered signal $S(r, \lambda)$ : (a) obtained along azimuth $185^{\circ}$ with respect to the North and at a zenithal angle of $51^{\circ}$ at 18:15 UTC on June 26th, for a beam crossing over two quasi-homogeneous layers (I and II). The transition between layers is denoted by the dashed line. (b) Obtained along azimuth $150^{\circ}$ with respect to the North and at a zenithal angle of $18^{\circ}$ at 16:04 UTC on June 26th, for a beam crossing over a succession of quasi-homogeneous (I), -heterogeneous (II), -quasi-homogeneous (III) layers. 
the different extinction coefficient of the layers. Both properties may be used, on each lidar beam, to measure the stratification altitude. Several techniques have been proposed for a precise layer transition measurement from the lidar signals; in the following sections, the Inflexion Point Method (IPM) which uses the lidar signal itself (Chen et al., 2001; Menut et al., 1999) will be primarily used. Each layer top altitude can be retrieved from the second derivative profile of the lidar signal multiplied by the squared altitude $\left(\partial^{2}\left(P z^{2}\right) / \partial z^{2}\right)$. For instance, $P z^{2}$ from Fig. 2 (diagram a) and its second derivative are both plotted in Fig. 3; the minimum value of this second derivative gives an altitude measurement of the intensity step of the lidar signal between layer I and layer II. It is worthwhile to note that these lidar signal observations are sufficient to retrieve the boundaries of the various layers.

The stratification analysis will however be completed by the addition of the spatial and temporal distribution of the extinction coefficient. Although this optical parameter cannot be directly linked to the local aerosol composition, the extinction spatial contrast between the different layers and also the extinction temporal variation inside each layer are elements that will be shown a greater relevance than the ozone concentration, to interpret the atmospheric dynamics. Moreover, the ozone concentration and the extinction coefficient are used to build vertical angular maps (Fig. 10) or time-altitude maps (Fig. 11) in order to analyse the large number of lidar shots in many different directions.

The extinction coefficient determination requires the assumption of a relationship between the extinction coefficient and the backscattering coefficient, and the knowledge of the extinction at a reference distance (Klett, 1981). If the atmosphere is locally homogeneous, the slope method (Carswell, 1983) represents a less constraining solution since the extinction coefficient can be approximated. The extinction can be

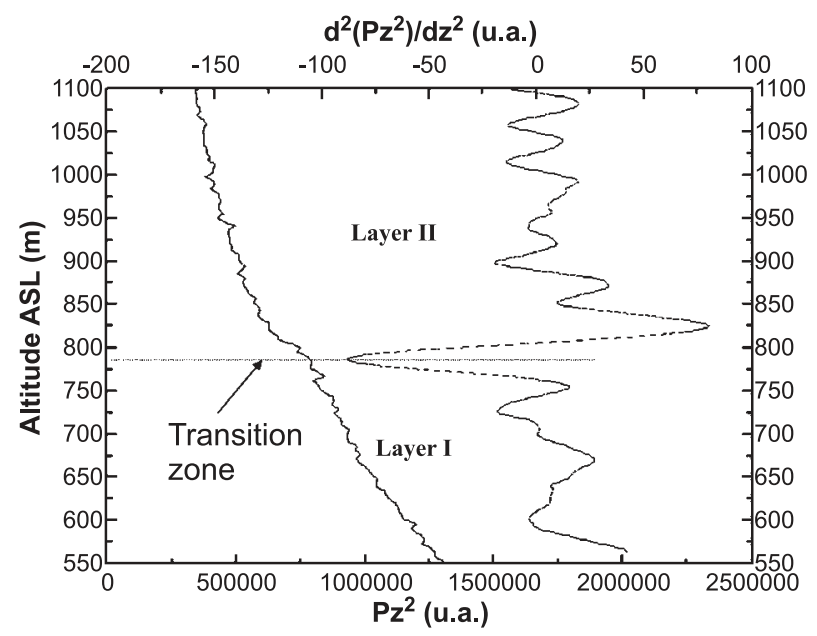

Fig. 3. Vertical corrected backscattered signal $S(r, \lambda)$ of Fig. 2a (solid curve) and its second derivative (dashed curve). The precise altitude of the transition between layer I and layer II is denoted by the dot line corresponding to the minimum of the second derivatives. 
determined by derivating the corrected backscattered signal and the backscattering coefficient:

$$
\alpha(r, \lambda)=-\frac{1}{2} \frac{\mathrm{d}}{\mathrm{d} r}[S(r, \lambda)]+\frac{1}{2 \beta(r, \lambda)} \frac{\mathrm{d}}{\mathrm{d} r}[\beta(r, \lambda)]
$$

The second part of this equation is negligible if the atmosphere is locally homogeneous, and the extinction is computed by determining the slope of the corrected backscattered lidar signal:

$$
\alpha(r, \lambda)=-\frac{1}{2} \frac{\mathrm{d}}{\mathrm{d} r}[S(r, \lambda)]
$$

Practically, the slope method is convenient as the atmosphere may be divided in homogeneous parts, but we must keep in mind that the extinction is not valid at the layers transition (corresponding to a rapid variation of $\beta$ ). In this study, only two principle cases need to be considered. Firstly, the backscattered signal $S(r, \lambda)$ is made of successive segments with different slopes (Fig. 2, diagram a) and the atmosphere is then considered as a succession of different quasi-homogeneous layers. The slope method is applied to approximate the extinction coefficient inside each layer but is not valid at the transition between the layers. In the second case, the atmosphere is heterogeneous, but contains homogeneous layers as shown by the lidar signal in Fig. 2 (diagram b). The stratification is then accessible by localising the homogeneous layers embedding the heterogeneous layer. The slope method and the inflexion point well complement each other to understand the stratification from lidar shots.

Finally, it must be noted that the total atmospheric extinction includes Rayleigh scattering, large size aerosol interactions (e.g. Mie) and molecular absorption. Here, the reference optical beam is also partly absorbed by ozone, but the ozone only weakly contributes to the general stratification (see Section 3.2.1).

\subsubsection{Stratification information from UHF radar}

As for the lidar, the discussion of atmospheric stratification with UHF wind profiler observations will be mainly based on the intensity of the backscattered signal. In UHFband the recognised dominant source of radar echoes in clear air is associated with turbulent scattering by air refractive index irregularities produced by spatial fluctuations of humidity and temperature due to turbulent mixing. It is the so-called Bragg scattering for which the backscattered power arises only from irregularities dimensions equal to half the radar wavelength. According to Ottersten (1969), the radar reflectivity $\eta$ is given by the formula (all the variables in mksa units):

$$
\eta=0.38 \lambda^{-1 / 3} C_{n}^{2}
$$

where $\lambda$ is the radar wavelength, and $C_{n}^{2}$ is the air refractivity index structure constant. The main assumptions imply the existence of the Kolmogorov turbulence inertial subrange and that $\lambda / 2$ is a spatial scale included in this subrange.

High $C_{n}^{2}$ values usually result from the conjunction of strong turbulent mixing and sharp vertical gradient of temperature and/or humidity. These favourable conditions are 
met in particular at the top (the entrainment zone) of the ABL where a layer of maximum radar echoes is usually observed. This feature is operationally used to accurately infer the ABL height Zi (Angevine et al., 1994). Actually, levels of local $C_{n}^{2}$ maximum give an indication of an interface between two different atmospheric layers. Note that the same type of information can be derived from sodars, which have a similar echoes source, except that they are only sensitive to temperature fluctuations.

Rayleigh scattering from particulate matter such as insects is a recognised potential source of UHF echoes in clear air ABL of secondary importance in the magnitude of the radar reflectivity compared to the turbulent Bragg scattering but that may induce an undesirable effect in the air vertical velocity measurement. In fact, according to Angevine (1997) and Lothon et al. (2002), UHF measurement of air vertical velocity in the ABL presents on average an unphysical systematic negative value ranging from -10 to $-30 \mathrm{~cm} / \mathrm{s}$ that might be explained by material scatterers that possess an intrinsic fall speed. This negative bias will not be overlooked when interpreting UHF vertical velocity fields affected by a possible underestimation.

The dissipation rate of the turbulent kinetic energy $\varepsilon$, which can be retrieved from the measurement of the UHF Doppler spectral width, is an important variable that will be used in the following analysis. The spectral width is linked to wind fluctuations within the radar resolution volume. These fluctuations are mainly due to the turbulent mixing and to the mean vertical wind gradient. The contribution of the spectral width due to the turbulence can be easily extracted and then it is possible to infer $\varepsilon$, which is one of the most fundamental parameters in the ABL understanding. Further details can be found for instance in Jacoby-Koaly et al. (2002).

\section{Atmospheric stratification and its dynamics on June 26th, 2001}

\subsection{Local meteorological conditions}

June 26th was the last day of the photochemically polluted IOP2b. A high pressure ridge, extending from Maghreb to the Northern Sea had been present over France for 3 days, with dry and warm air at all levels and is shifted towards the East of Europe. The synoptic wind was blowing from South-East at 12:00 UTC. The surface pressure gradient was weak and prone to sea breeze development.

The MesoNH-C simulations (not shown here) forced by the 9-km mesoscale model indicate an oscillation of the synoptic wind $(3000 \mathrm{~m})$ over the area from West (6:00 UTC) to South (9:00 to 11:00 UTC), South-West (12:00 to 16:00 UTC) to West again at 17:00 UTC.

In this study, the meteorological conditions were provided by five different means (surface stations, sodars, UHF radar, Constant Volume Balloon (CVB) and radiosoundings) that brought complementary space and time information and highlighted the complexity of the flow in the area.

Horizontal ground wind velocities were collected from four meteorological stations (Fig. 1) located downtown at 'Observatoire' (Obs) (LA/CRA), 'Hippodrome' (Hipp) (Météo France), 'Groupement de laboratoires de Marseille' (GLM) (Coria), 'Cour d'Appel 
Administrative de Marseille' (CAAM) (Indiana University) and two additional sites in the northern suburb of Marseille at Vallon Dol (Météo France/CNRM) and St Jérôme (LMF, $\mathrm{CNRS} / \mathrm{ECN}$ ). The altitude and shortest distance to the sea of the various ground stations are indicated in the figure caption. Fig. 4 displays the surface wind speed and direction on June 26th and reveals a sea breeze day at the different sites. The flows characteristics in the various ground stations suggest the following classification:

(1) Well-developed sea breeze flow coming from South-West or West at Vallon Dol and St Jérôme and remaining the whole day long.

(2) Rapid change of the westerly sea breeze flow into a southerly sea breeze flow at Obs, CAAM and Hipp.

(3) Well-developed sea breeze flow coming from the South at GLM and remaining the whole day long. GLM is situated at approximately the same distance from both western and southern coasts, but is downwind some kind of gap in the Calanques ridge, which may favour the southern flow.

In the first case, the wind direction change occurs in the morning at about 8:00 UTC (diagrams $a$ and $b$ ) with a veering of the wind of about $120^{\circ}$ at Vallon Dol and $180^{\circ}$ at St Jérôme. This wind direction change is accompanied by a weak decrease of the temperature (Fig. 5). The Vallon Dol and St Jérôme flow directions are perpendicular to the coastline and they prevail during all the day until 18:00 UTC, with a $4 \mathrm{~m} / \mathrm{s}$ maximum wind speed at 14:00 UTC.

In the second case at Marseille, the sea breeze (north-westerly component) starts at about 8:00 UTC (Fig. 4, diagrams c, d, e) but at Hipp, it starts slightly sooner, probably because of the shorter distance to the sea. Then, in the middle of the day, a southerly wind flow is observed progressively: it turns South-East at Hipp (probably due to the Marseille-Veyre Mountain) at 10:00 UTC, South at 12:00 UTC at CAAM and at 14:00 UTC at Obs. These changes in wind direction are accompanied by a weak temperature decrease at Obs and CAAM that is not observed at Hipp, probably due to the hourly data average (Fig. 5, diagrams c, d, e). This sea breeze prevails during the rest of the day until 20:00 UTC with a maximum wind speed of $9 \mathrm{~m} / \mathrm{s}$ (Hipp) and $5 \mathrm{~m} / \mathrm{s}$ (CAAM) at 14:00 UTC. At Obs however, the wind direction fluctuates and the wind speed is rather slow $(<2 \mathrm{~m} / \mathrm{s})$.

In the last case, the southerly flow is observed from 8:00 until 20:00 UTC (Fig. 4, diagram $\mathrm{f})$ with a maximum speed at 10:00 UTC $(3.5 \mathrm{~m} / \mathrm{s})$.

This sea breeze is likely to be a result of the weak mesoscale pressure gradient on this day. Its evolution illustrates a confrontation between the westerly and southerly sea breezes influenced by topographic features such as the coastline and hills especially in southern Marseille (Calanques ridge). At CAAM and Hipp, the sea breeze turns from NW to $\mathrm{S}$ or $\mathrm{SE}$ when its speed is strong enough for the flow to pass over the Calanques ridge. However, the flow decelerates at Obs after this veering, so the westerly sea breeze dominates in the northern ground stations.

The Vallon Dol sodar confirms information obtained from the Vallon Dol surface station, at its lowest level (Fig. 6). In the middle of the day and higher in the ABL, it indicates a flow turning from SW (surface) to South $(600 \mathrm{~m})$ and then to SE. This 


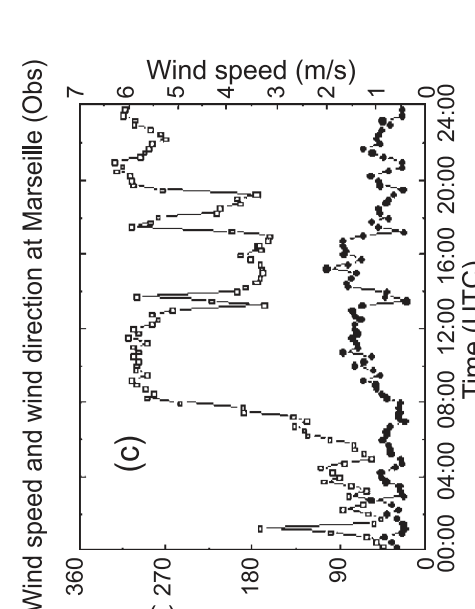

(。) uо!ฺәәџ!р pu!M

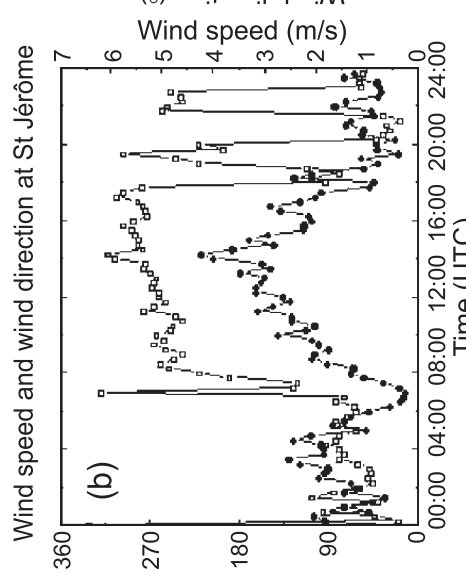

(॰) ио!ฺэәд!р pu!M

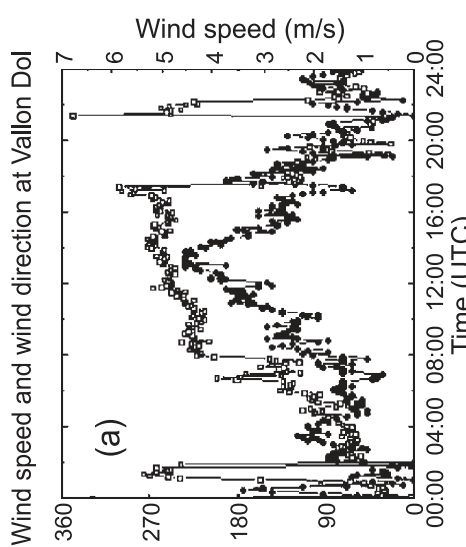

(.) uo!̣юәд!p pu!M

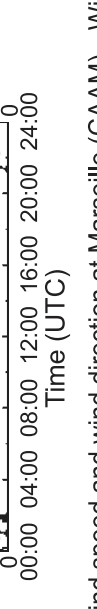

产

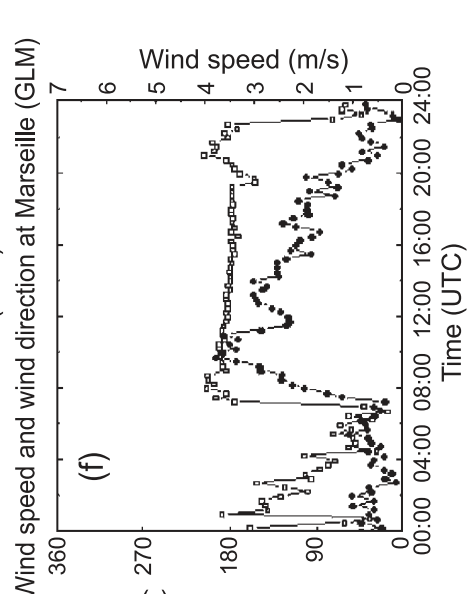

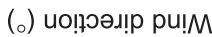

Wind speed $(\mathrm{m} / \mathrm{s})$

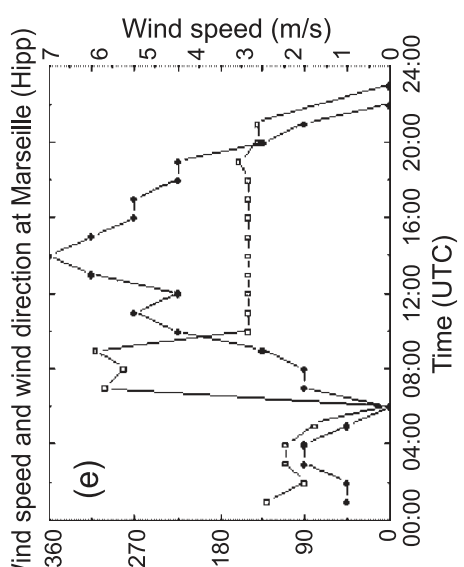

(。) uo!̣วәц!p pu!M

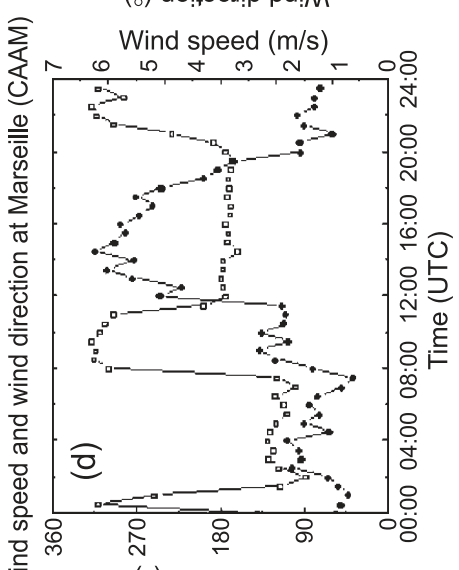

(。) uо!ฺวәц!р pu!M

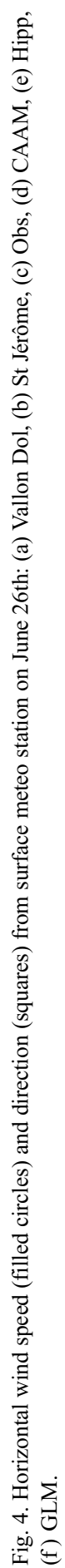



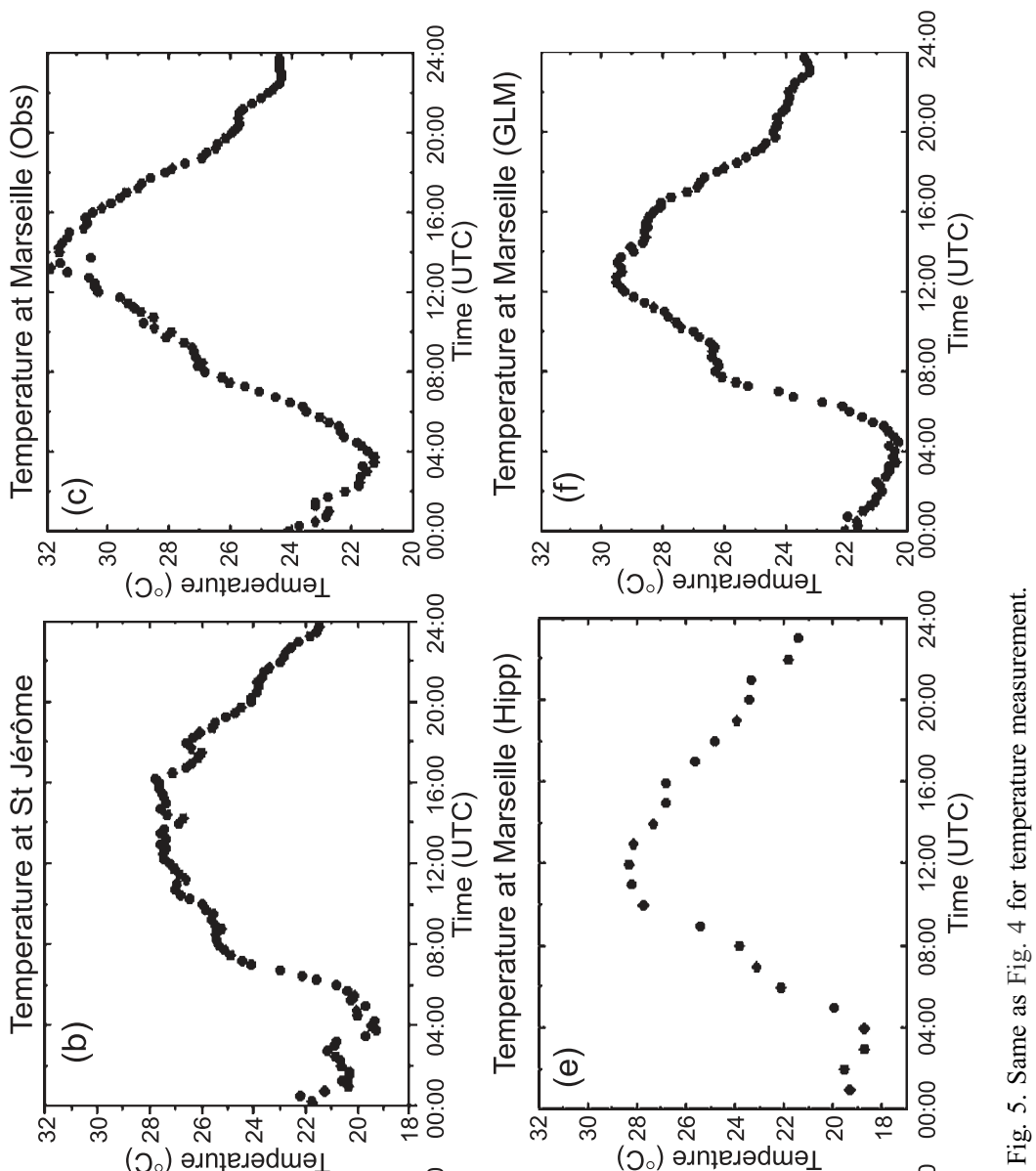

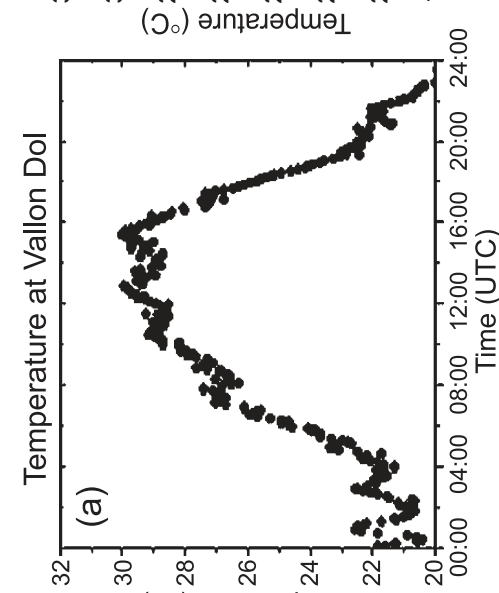

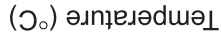

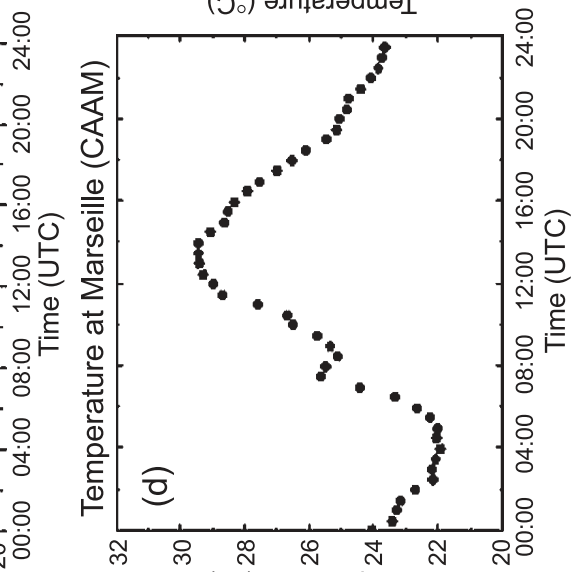

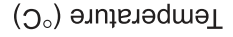




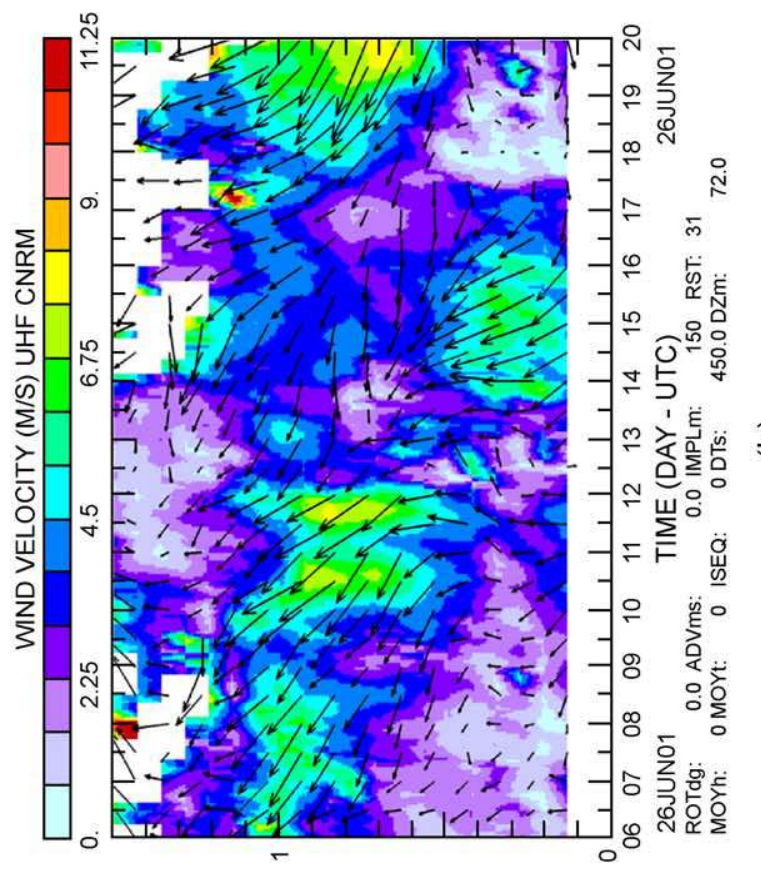

(าSW/WY्र) $\exists a \cap \perp \perp 7 \forall$

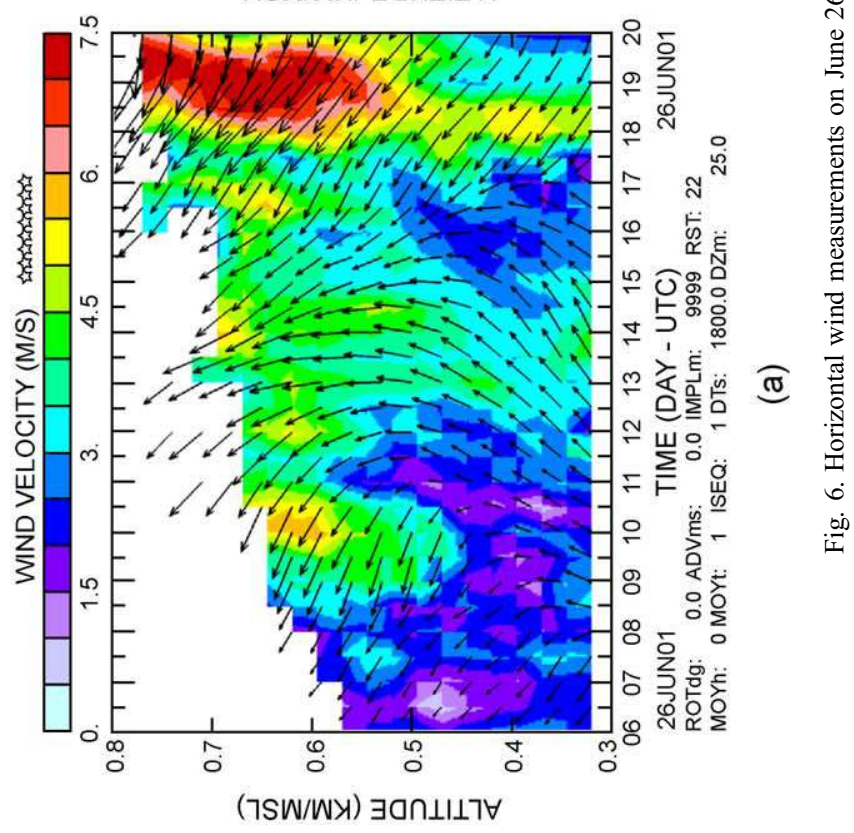


information is also validated by the wind measurements of the constant volume balloon (CVB) launched from Vallon Dol (LA, CNES, CNRM) at 14:00 UTC (Fig. 7).

The downtown UHF radar at Obs (Fig. 6) did not observe the north-westerly wind direction measured at the Obs surface station in the morning. It means that the height of the north-westerly sea breeze flow is not deep enough to be observed by the radar. Moreover, the radar duplicates the sodar information with some difference in the lowest level. At approximately 14:00 UTC, the radar indicates a node of strong southerly wind below $500 \mathrm{~m}$ asl that is followed by a calm period, whereas the sodar shows this disturbance as a southerly wind flow above $500 \mathrm{~m}$ asl.

The temperature conditions at the ground can be retrieved both from the balloon (Fig. 7) ascents from Vallon Dol and radiosoundings (Fig. 8) launched from Obs (Météo France/ CNRM). Both highlight a very complex structure of the ABL during the day, confirming the dynamics presented with the sodar.

At 14:00 UTC the CVB ascent exhibits three layers:

- An unstable layer near the surface up to $500 \mathrm{~m}$ with colder and wetter air coming from West to Southwest.

- A $2{ }^{\circ} \mathrm{C}$ warmer and $2.5 \mathrm{~g} / \mathrm{kg}$ drier layer between 500 and $850 \mathrm{~m}$ with South to SouthEast stronger wind.

- Existence of a transition on matching layer (850-1150 m) separated from the former layer by a strong temperature and humidity gradient.

The three radiosoundings at 12:00, 14:00 and 16:00 UTC exhibit a similar stratification with the two boundaries at 300 and $700 \mathrm{~m}$ increasing to 400 and $800 \mathrm{~m}$. The upper 'matching layer' occurs from 14:00 UTC only and spans from 800 to $1000-1100 \mathrm{~m}$. The GPS signal on the rawisoundings failed on this day, so the origin of the various layers could not be clearly identified.

\subsection{Boundary-layer dynamics by comparison of lidar and UHF radar measurements}

\subsubsection{Temporal evolution of the stratification from the UV lidar}

On June 26th, the vertical angular scans were achieved with the $185^{\circ}$ and $150^{\circ}$ azimuth angles, with a $10^{\circ}$ angle step in the $\left[-80^{\circ}, 90^{\circ}\right]$ zenith angle range. The continuous monitoring from 5:00 UTC until 20:00 UTC, except for maintenance between 8:30 and 9:30, allows the examination of the whole lower troposphere evolution in either extinction coefficient or the ozone concentration. Nevertheless, the extinction parameter exhibits a clearer stratification than the ozone concentration. As a guideline, the temporal evolution of the extinction versus altitude is plotted in Fig. 9, derived from angular scan treated to produce a characteristic in the vertical direction. Four events are emphasised on this figure, representing the different kinds of stratification that can be encountered from the sea breeze start at 8:00 UTC to its end at 18:00 UTC. Each event is also illustrated in Fig. 10 by the corresponding vertical angular scan of the extinction.

3.2.1.1. Sea breeze stratification until 12:00 UTC. Before the onset of the sea breeze, the atmosphere does not exhibit any clear stratification though the extinction is slowly 


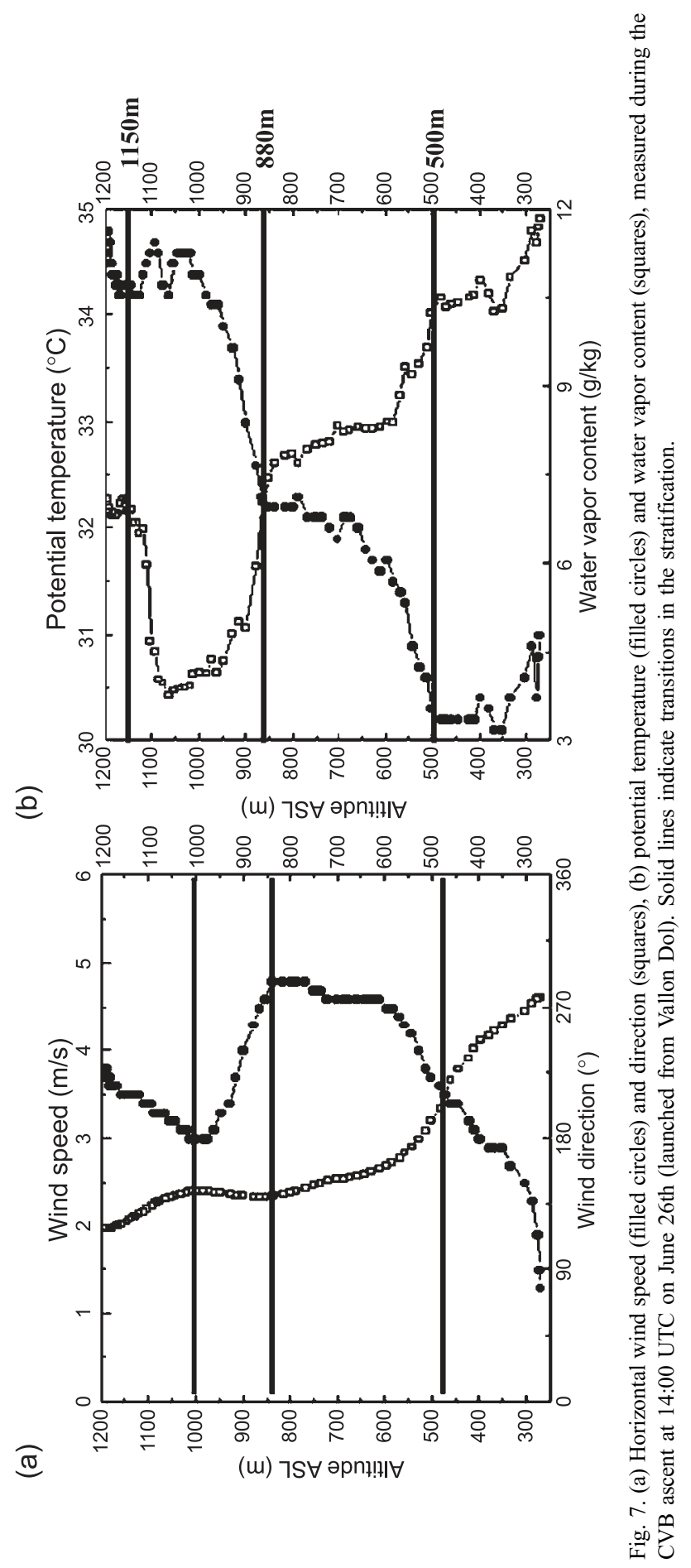




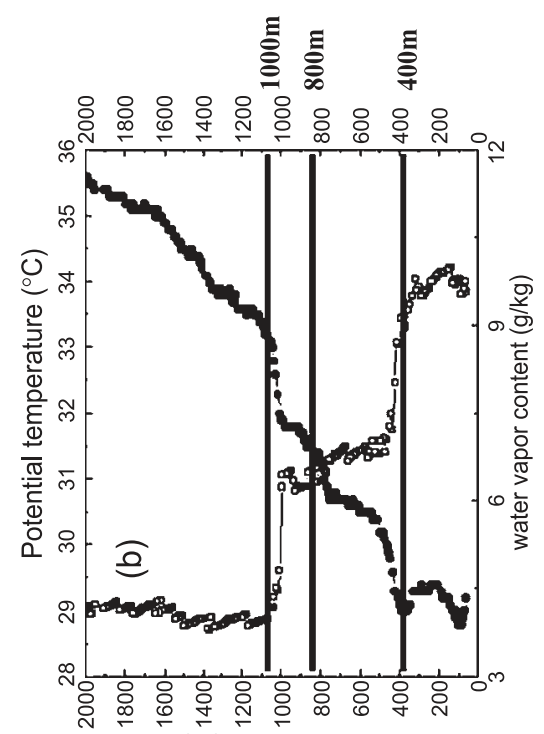

(w) $\urcorner S \forall$ әрп!!!| $\forall$
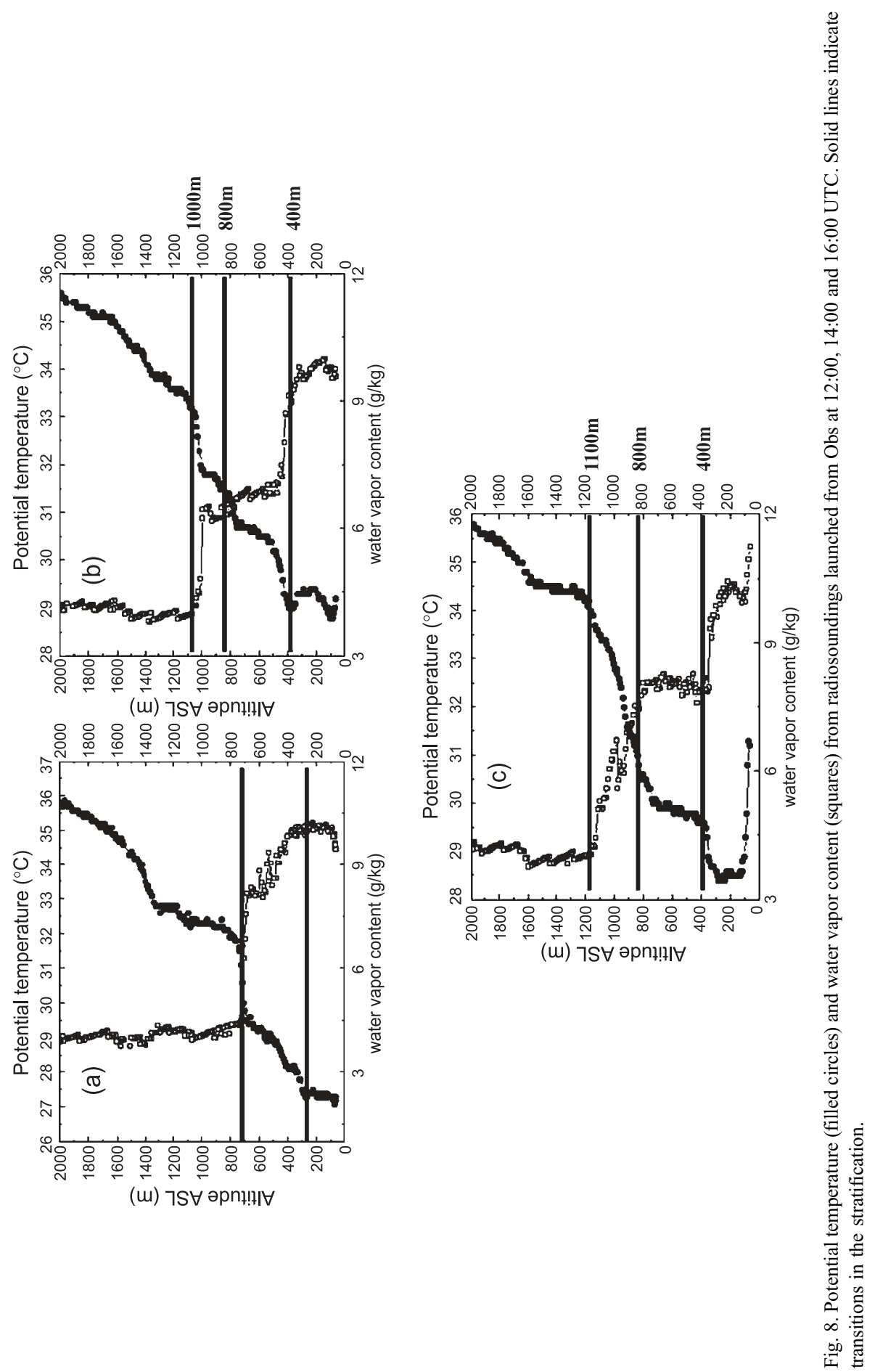


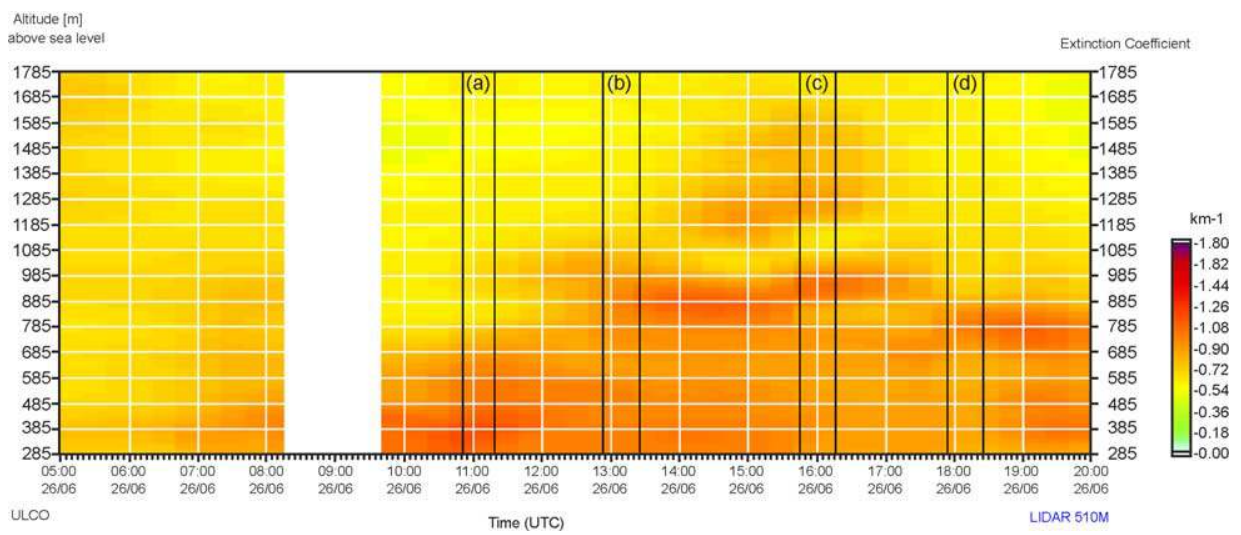

Fig. 9. Temporal evolution of the extinction coefficient versus altitude. Periods (a), (b), (c) and (d) are linked to vertical angular scans in Fig. 10.

increasing. The atmosphere becomes clearly stratified when the sea breeze occurs. By examining Figs. 9 and 10, the stratification below a $2 \mathrm{~km}$ altitude primarily consists of a structure with two regions. The lower region height increases in the morning to stabilize approximately at an altitude of $750 \mathrm{~m}$ at 11:00 UTC. However, fine analysis of the lidar signal using the IPM allows a sub-structure of the lower region to be distinguished from ground to $480 \mathrm{~m}$ asl. This sublayer is scarcely visible in Fig. 9, but clearly appears in Fig. 12 , that displays a higher concentration of ozone up to $485 \mathrm{~m}$ at 11:00 UTC. This thin layer may be linked to the South-West/West sea breeze previously pointed out at Vallon Dol from ground and sodar measurements (Section 3.1).

3.2.1.2. Low region elevation. After a short transition between 12:00 UTC and 13:00 UTC, the lower region height increases up to about $1 \mathrm{~km}$. The corresponding extinction vertical scan is displayed in Fig. 10 (diagram b) to be compared with diagram a.

3.2.1.3. Interface layer occurrence. The stratification strongly changes after 14:00 UTC with the growth of a new layer, which will be referred to as an "interface layer" (between 785 and $1185 \mathrm{~m}$, from 14:30 to 18:00 UTC). Indeed, the lidar signals exhibit a triple regions structure comparable to the signal of Fig. 2 (diagram b), indicating that an heterogeneous region is embedded in two homogeneous regions. The vertical angular scan of Fig. 10 (diagram c) gives a clear picture of the vertical stratification with an interface layer delimited by the vertical arrow. Let us note that the green lines on this diagram correspond to the transition between the different regions and are helpful for pointing out the transitions even if the slope method is no longer valid here. This stratification remains during the whole afternoon. An accurate analysis of the stratification at very low level indicated that the thin SW-W sea breeze sublayer extending from ground to $500 \mathrm{~m}$ could not be detected by the lidar after 14:00.

3.2.1.4. Sea breeze end. The previous stratification disappears at the end of the sea breeze at 18:00 UTC and is then replaced by a main double regions structure (Fig. 10, diagram d). 


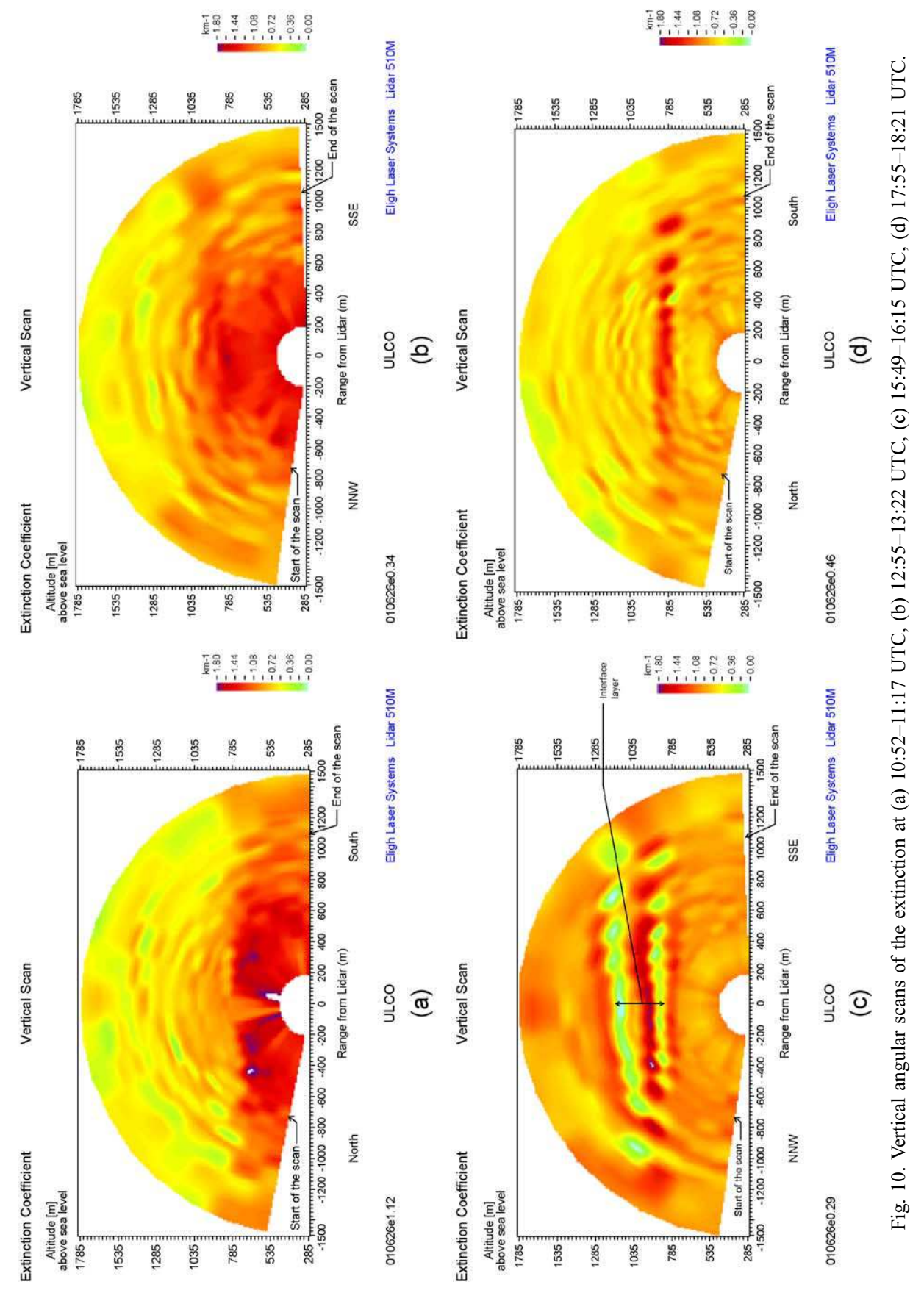


Identification of the spatial and temporal location of these various superimposed layers will help to understand the dynamics. The precise position of the various regions is measured directly on the lidar backscattered signals. In summary: If the atmosphere exhibits a structure consisting of multiple homogeneous regions, the transition between successive homogeneous regions is recognized by a jump and a slope variation on the lidar signals $S(r, \lambda)$ and its height is precisely measured by using the IPM. This transition is represented in Fig. 11 and the following figures, by a point drawn by rectangles, diamonds or triangles according to the layers height.

If the atmosphere exhibits structure containing multiple heterogeneous zones, only the homogeneous regions are identified with green bars breaking at the border of heterogeneous areas. In this way, the 'interface layer' is located in the area between two homogeneous regions (Fig. 11).

The top height of each layer is superimposed, on the extinction distribution, determined with the slope method (Fig. 11), showing that the extinction distribution is coherent with the regions transition height and displaying the extinction variation inside the layers. For instance, in the morning, the extinction is increasing in the sea breeze flow below $500 \mathrm{~m}$. The regions position may also be superimposed on the ozone map (Fig. 12), allowing a correlation between the dynamics of the lower troposphere and the ozone concentration. From the sea breeze onset to 12:00 UTC, the ozone maximal concentration is localised in the sublayer below $500 \mathrm{~m}$ with about $160 \mu \mathrm{g} / \mathrm{m}^{3}$, leading to about $25 \%$ ozone contribution to the extinction. Between 12:00 and 13:00 the ozone concentration decreases in the same sublayer down to $90 \mu \mathrm{g} / \mathrm{m}^{3}(12: 15 \mathrm{UTC})$ so that it reaches a concentration close to that in the 500-1000 m overlying sublayer. After 13:00, the low level maximum appears again, to be replaced after 15:00 by an homogeneous

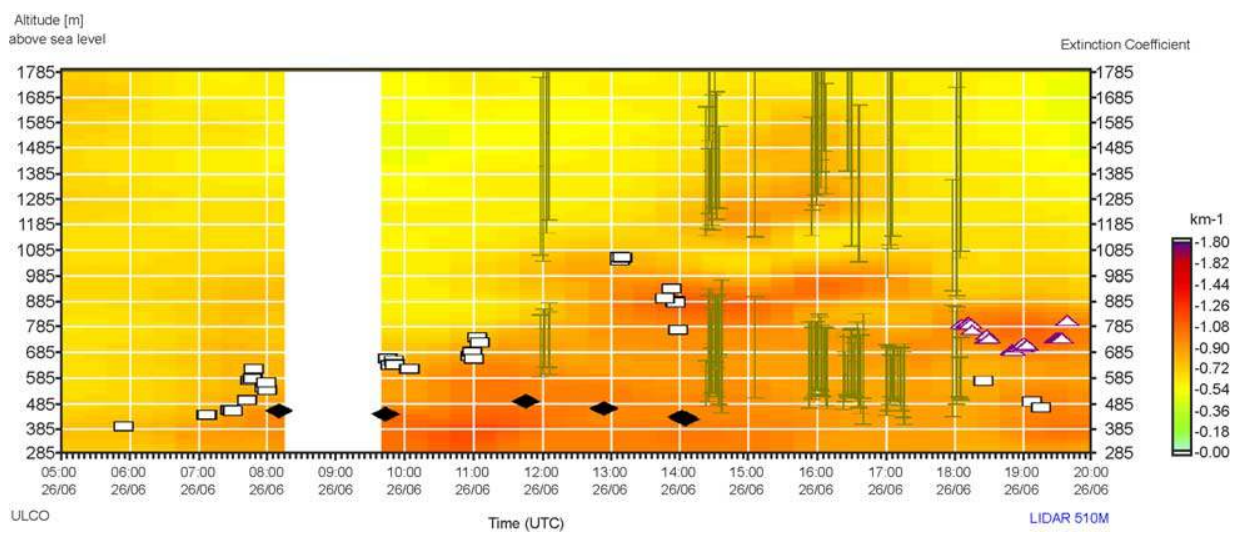

Fig. 11. Stratification transitions are superimposed with the temporal evolution of the extinction. A double layer structure is represented by the transition between two layers (rectangles). If the main layer gets a sub-structure, diamonds characterize the height of sub-layers transition. Triple layer structure is represented only by the position of the quasi-homogeneous layers (green bars) embedding the interface layer. Triangles denote the residual layer height. Note that the lower limit of green bars near $400 \mathrm{~m}$ only correspond to the starting measurement distance of the selected lidar beams, and so, cannot considered as the layer border. On quasi-horizontal lidar beams, the transition between layers cannot be detected and the sea-breeze flow is not represented after 14:30. 


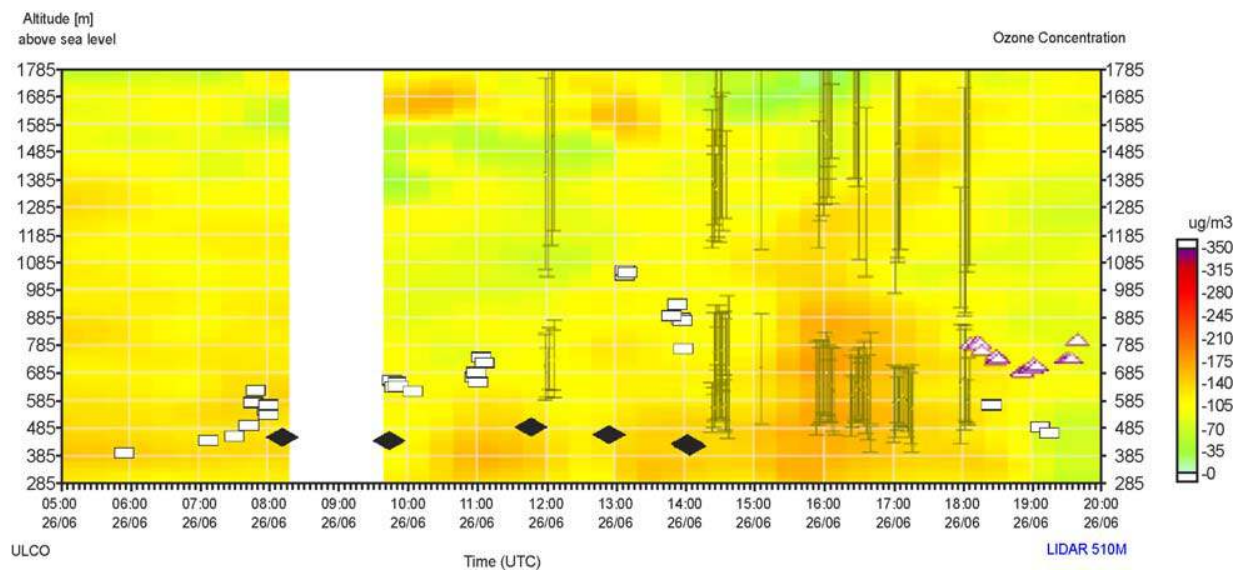

Fig. 12. Stratification transitions are superimposed with the temporal evolution of ozone concentration.

concentration on the whole depth 300-1000 $\mathrm{m}\left(170 \mu \mathrm{g} / \mathrm{m}^{3}\right.$ at 16:00 UTC). As a conclusion for these preliminary observations, it has to be noted that the ozone distribution is not always correlated with the stratification stemming from the total extinction: the ozone concentration is not, if used alone, a good indicator for analysing the stratification in the present case.

\subsubsection{Temporal evolution of the stratification from the UHF radar and comparison with lidar observations}

For the same period and altitude previously analysed by the lidar, Fig. 13 present height-time sections of the radar reflectivity, horizontal wind speed, $\varepsilon$ and vertical motion, that will be used to analyse the atmospheric stratifications as seen by the UHF wind profiler.

In the radar reflectivity section (diagram a) displayed in term of $C_{n}^{2}$, local reflectivity maxima which represent, as explained above, boundaries between different atmospheric layers, are delineated with continuous or hatched curves. These particular UHF interfaces are superimposed with the lidar and radiosoundings observations in Fig. 14. At a first glance, it is clear that there is a good correspondence between atmospheric features observed by the lidar and by the wind profiler. Note that due to a receiver blockage, reflectivity values below $350 \mathrm{~m}$ are unreliable.

The most important interface determined by the UHF profiler is presented in Fig. 13, diagram a, with a continuous line that starts at 06:00 UTC at a height of $350 \mathrm{~m}$, reaches $750 \mathrm{~m}$ at 12:00 UTC, and ends at level $350 \mathrm{~m}$ at about 17:00 UTC. This boundary can be considered as the UBL top. It is nearly coincident with the lowest isothermal or inversion layers observed by balloons (see pink and brown circles in Fig. 14). It is also below this line that turbulence is concentrated as shown in Fig. 13 (diagram c). The morning ascent of the UBL top seen by the UHF radar is very close to the second interface observation of the lidar (squares in Fig. 14). On the other hand, the afternoon descent of the UHF UBL top is coincident with the inversion layer measured by radiosoundings and close to the lowest interface layer determined by the lidar. In fact, the collapse of the UBL is linked as shown 
a

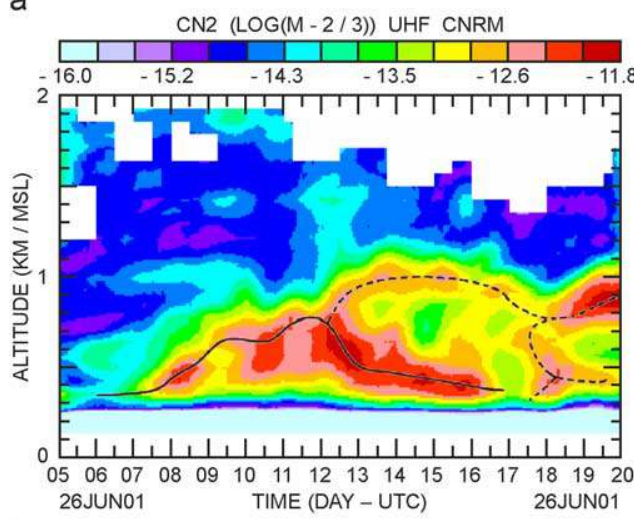

b

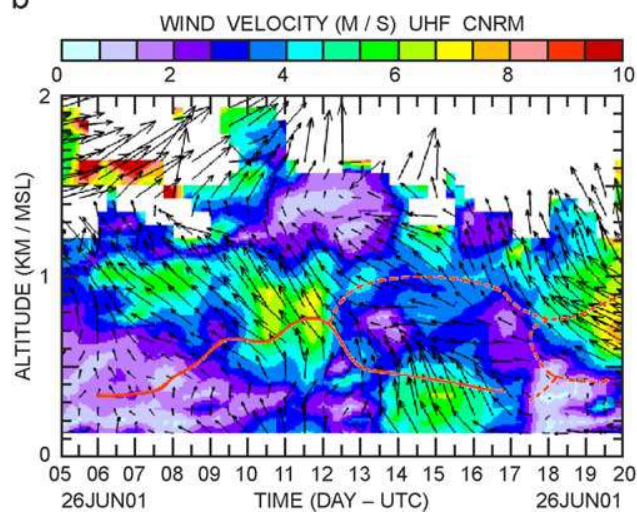

C

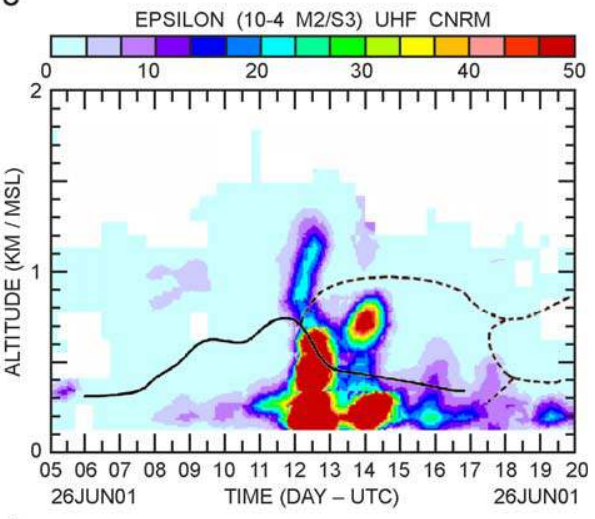

d
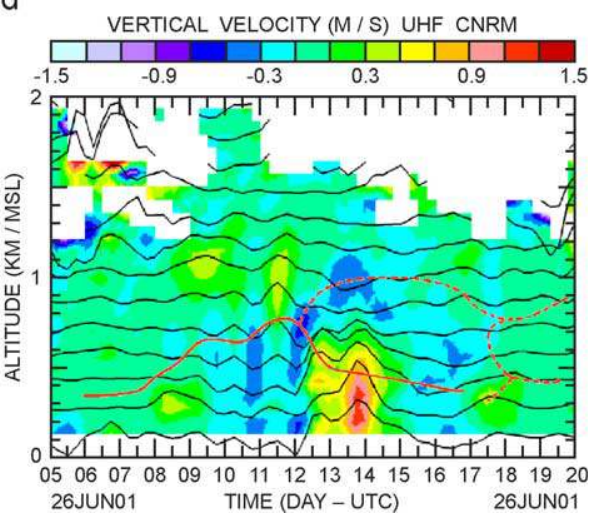

Fig. 13. Time-height sections derived from UHF profiler observations made on July 26th 2003: (a) radar reflectivity in terms of $C_{n}^{2}$, (b) horizontal wind speed, (c) dissipation rate of turbulent kinetic energy $\varepsilon$, and (d) vertical wind speed. For clarity a running average over half an hour was applied. Superimposed curves are drawn along local reflectivity maximum.

in Fig. 13 by an increase of the sea breeze flow after 13:30 UTC and then to an accentuation of the maritime cool air. This evolution of the urban boundary layer followed by a collapse due to the sea breeze intensification is well described in Puygrenier et al. (2004).

In the morning, it has been noticed previously that a South-West/West sea breeze is blowing below $500 \mathrm{~m}$ at Vallon Dol. This sea breeze is not visible at Obs by the UHF radar. Even if the 12:00 radiosounding (Fig. 8) indicates a slightly colder sublayer from 0 to $300 \mathrm{~m}$ at $\mathrm{Obs}$, the water vapour gradient is not steep enough to be detected by the radar. In the middle of the morning, northern sites and southern sites undergo two different sea breeze conditions: SW for Vallon Dol, W at the ground for Obs and S for GLM, Hipp, CAAM. The Obs station is situated $10 \mathrm{~km}$ from the southern coast, and Vallon Dol $5 \mathrm{~km}$ from the western coast. The vertical development of the southern breeze is consequently higher above Obs and it is also supported by the feed of warm urban air. Whatever the wind direction at low level at Obs, the southern (S-SE) sea 


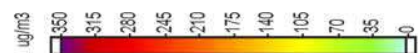
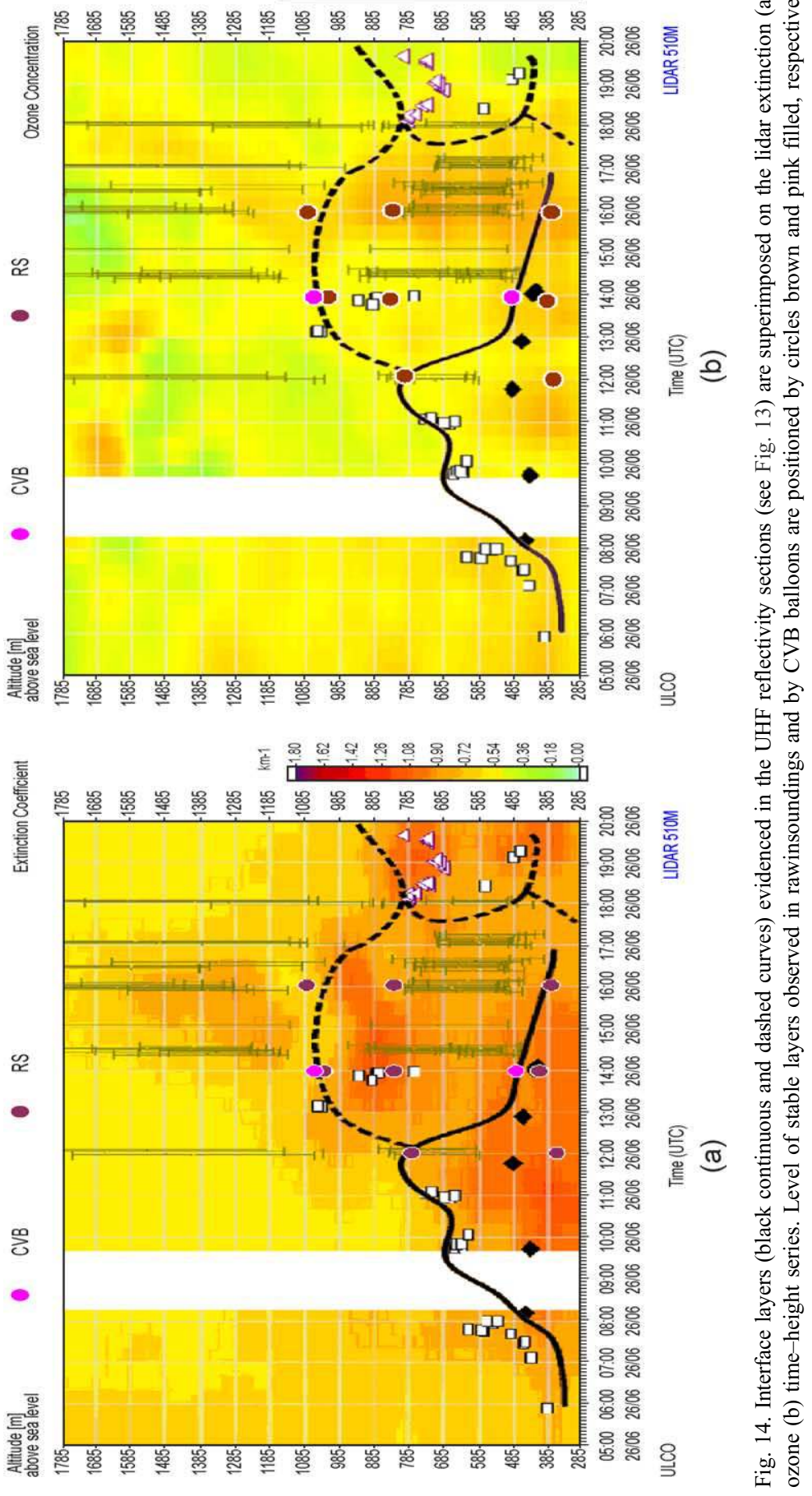
breeze extending up to $800 \mathrm{~m}$ is advected to the North (to Vallon Dol) where it surmounts the colder western sea breeze of the lower level (Fig. 6). This mechanism is helped by the slope effect inducing an ascent of the air between Obs $(60 \mathrm{~m}$ asl $)$ and Vallon Dol (285 $\mathrm{m}$ asl).

At 12:00, the wind becomes very low at Obs (Fig. 13, diagram b) and turbulence (diagram c) bursts out. This sketch of strong sea breeze/weak turbulence followed by weak sea breeze/strong turbulence is well explained in Puygrenier et al. (2004). The turbulence is strong enough to destroy the inversion between the westerly and southerly sea breeze in Vallon Dol: consequently, the ozone is mixed and its concentration becomes homogeneous between 300 and $1000 \mathrm{~m}$ (Fig. 12).

After 12:30 UTC, the southern sea breeze sharply increases at Obs, turbulence decreases and the UBL collapses. This is the time when the surface breeze that had been observed at the Obs ground station (Fig. 4) suddenly veers to South. This veering is accompanied by an increase of the vertical velocity (negative up to now, behind the Calanques ridge) which reaches $1 \mathrm{~m} / \mathrm{s}$ (Fig. 13). This can be explained by the sudden acceleration of the southern component, which brings enough kinetic energy to blow over the Calanques ridge and climb again along the Etoile ridge. The convergence of both breezes at Vallon Dol (western and southern flow from Obs) may induce a convergence and consequently a vertical ascendance in the lowest layers. After 14:00 UTC, the shear stress at $500 \mathrm{~m}$ generated by the easterly upper wind (Fig. 13) may destroy this vertical component.

The most complicated period of stratification extends from about 12:30 UTC, the beginning of the UBL collapse, until 18:00 UTC that corresponds to the end of the sea breeze at most sites. During that period the UHF clearly detects a second layer above the UBL (Fig. 14), reaching $1000 \mathrm{~m}$. This upper level is located inside the 'matching layer' observed by the CVB (850-1150 $\mathrm{m}$ at 14:00 in Fig. 7) and radiosoundings (800-1000 $\mathrm{m}$ at 14:00 in Fig. 8). This is expected as the $C_{n}^{2}$ relative maximum shown in Fig. 13 is generated by the sharp water vapor gradient observed on the soundings. Moreover, this interface is located at the lidar interface layer described in Section 3.2.1 (between green vertical bars).

So at 14:00 UTC, the situation may be summarized as follows: between 300 and $400 \mathrm{~m}$, which is the UBL top, and $850 \mathrm{~m}$, the wind is blowing from East at Obs (Fig. 13) and is disconnected from the surface southern sea breeze wind. Although soundings indicate a stable stratification, turbulence remains strong in this area with $\varepsilon$ values greater than $10^{-3} \mathrm{~m}^{2} \mathrm{~s}^{-3}$ (Fig. 13). This means that this air mass coming from East is not in equilibrium at both its boundaries. The turbulence inside, enhanced by the shear stress, tries to reach equilibrium, without succeeding since there is no thermic source at the lower boundary. There are two possibilities for the origin of the air advected from the East: either it is continental air with a rather developed mixed layer, or a sea breeze air mass that has been shifted by relief or mesoscale circulations to the area. Anyway this air mass appears to have undergone a slight gap-flow acceleration to the East of Obs and diverges at Vallon Dol (16:00 UTC). This advected air mass is capped by an interface, characterized by strong thermodynamic gradients just below the supposed free troposphere. An additional surprising feature, between 15:00 and 17:30 UTC, is the similar ozone concentration at Vallon Dol between the 
mixed layer under $300-400 \mathrm{~m}$ and this area between 300 and $400 \mathrm{~m}$ and $850 \mathrm{~m}$ as shown before. No explanation except coincidence has been found up to now: anyway it is very unlikely that the two superposed layers have merged as it happened near 12:00 UTC.

After 17:30 UTC, which corresponds to sea breeze end at Obs (Fig. 13), the UHF radar detects two other interface layers at about $400 \mathrm{~m}$ and $800 \mathrm{~m}$ altitude (hatched lines in Fig. 13). These features are nearly coincident with the interfaces determined by the lidar during this period (Fig. 14). According to Fig. 13, there is an important change in wind direction and magnitude, collocated with these boundaries.

\subsection{Discussion and comparison with MesoNH simulations}

In the previous subsection, a mechanism of competition between two sea breezes has been observed in the morning at ground stations. In both cases, thermal turbulence is limited, due to the cooling effect of the marine air advected by the sea breeze.

After a short period of active thermal turbulence due to the south sea breeze weakening (just after 12:00 UTC), another scheme prevails with the superposition of four layers:

- A thin UBL layer under $500 \mathrm{~m}$ with southern wind.

- A homogeneous layer [500-850 m] with eastern wind at Obs turning south-eastern at Vallon Dol.

- An interface layer [850-1150 m] with south-eastern wind.

- The supposed free atmosphere above.

In the present subsection, we will check whether this complicated sketch can be retrieved in the MesoNH-C simulations obtained for this last day of IOP2b. Fig. 15 presents the wind conditions obtained with the model at different levels in the ABL: the wind is rather weak in the Marseille area ( 2 to $5 \mathrm{~m} / \mathrm{s}$ ) and indicates a prevailing direction from South-East $(500 \mathrm{~m})$, slightly veering to South $(1000$ and $2700 \mathrm{~m})$. The wind field view corresponds to the area of the $3-\mathrm{km}$ mesh grid model (diagram a) that is enlarged at the lowest levels (diagrams $b$ to $d$ ). We wondered whether this wind flow which is steady and homogeneous over the sea might be pure sea breeze or could be linked to the synoptic flow. Fig. 16 shows the situation at level $500 \mathrm{~m}$. The flow is roughly southern, on the western part of the domain, between 6:00 UTC and 14:00 UTC. The Marseille area that has been designed by a rectangle is not windy at 6:00 UTC (diagram a). A low South wind has set up at 11:00 UTC (diagram b), which diverges on both sides of the large scale relief. We conclude that there is a superposition of a mesoscale sea breeze (in opposition to the local sea breezes observed close to the surface at the ground stations) and a southern synoptic component that is obvious up to level $2700 \mathrm{~m}$ (diagram a). The mesoscale sea breeze would be enhanced by the large scale relief shown in Fig. 16 (higher temperatures on slopes).

So the simulations account well for this southern component. It is important to determine the location of the local circulations that have been emphasized in the 


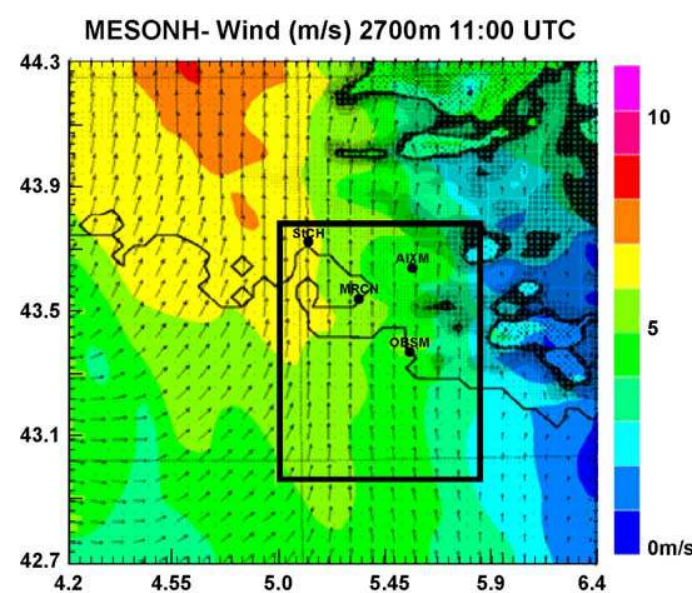

(a)

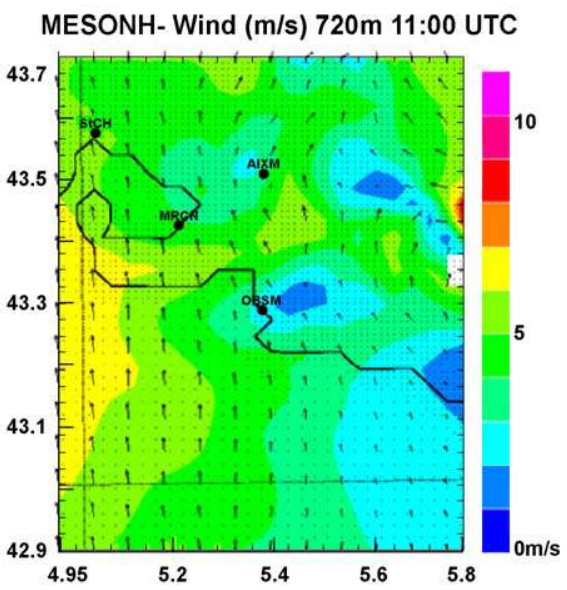

(c)
MESONH- Wind (m/s) 1000m 11:00 UTC

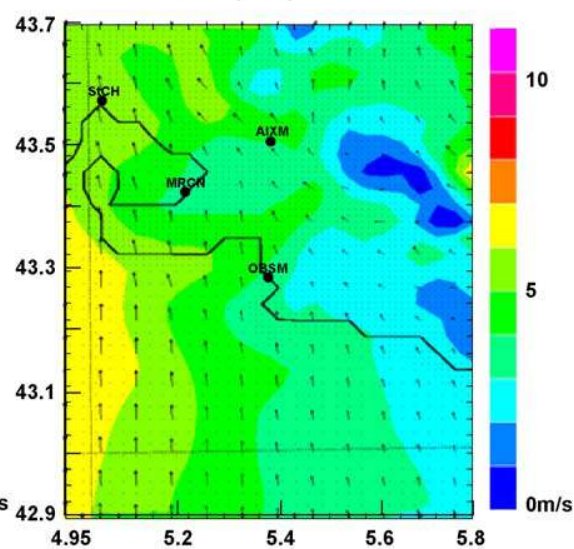

(b)
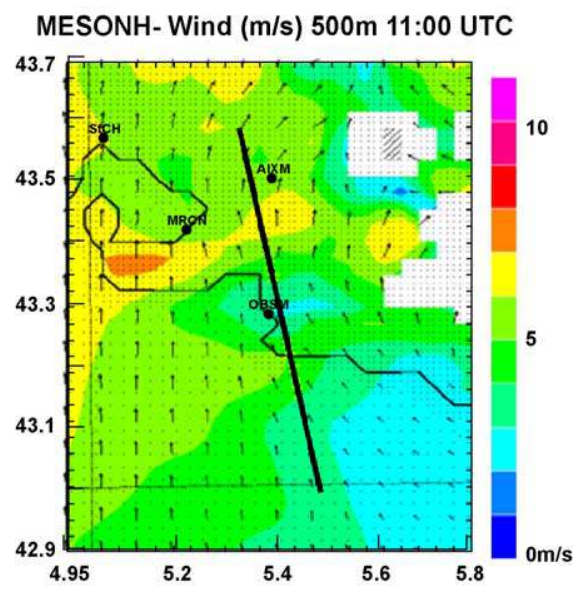

(d)

Fig. 15. MesoNH-C simulation on June 26th at 11:00 UTC on the smallest domain: wind vector and wind speed (color scale): (a) $2700 \mathrm{~m}$. Zoom on the Marseille area in (b) $1000 \mathrm{~m}$, (c) $720 \mathrm{~m}$ and (d) $500 \mathrm{~m}$. The black line indicates the horizontal track of the vertical cross-section in Fig. 17, the black rectangle the zoomed area.

previous sections, at Obs and Vallon Dol. Fig. 17 displays the dynamics, thermodynamics, ozone concentration and turbulence obtained by the model at 14:00 UTC on a south-north vertical cross-section whose track at the surface is indicated in Fig. 15 (diagram d).

The vertical structure of the horizontal wind reveals a complexity that is very similar to the conditions described in the previous subsections:

- A south-eastern flow is blowing over the sea (left part) between 200 and $800 \mathrm{~m}$.

- This flow speeds up over the Calanques ridge and decelerates (SE) over the city center (Obs). 
(a)

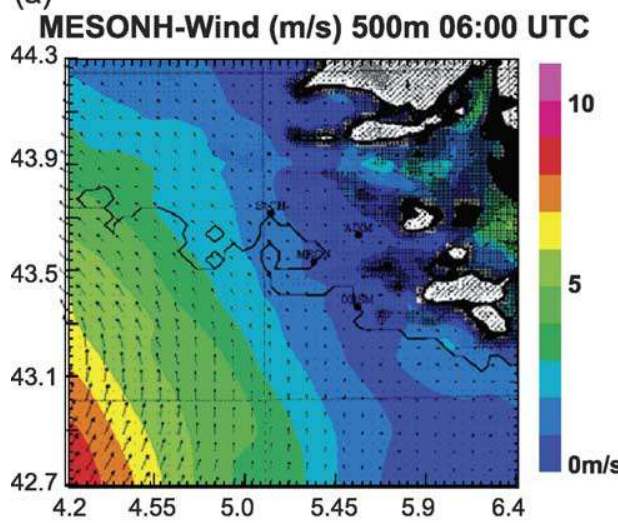

(b)

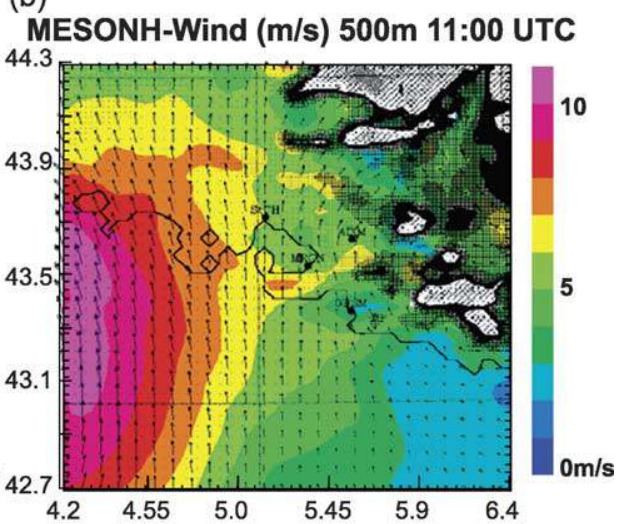

(c)

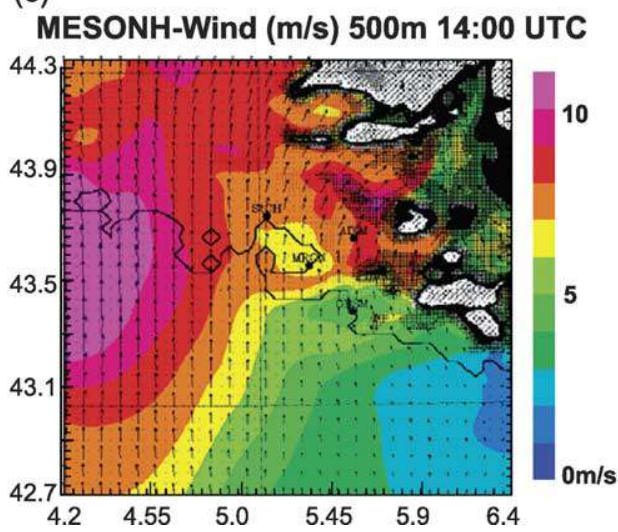

Fig. 16. MesoNH-C simulation on June 26th at $500 \mathrm{~m}$ asl (small domain) at 6:00, 11:00 and 14:00 UTC.

- Another layer (500 m deep) appears to the North, starting with the relief, with a western flow consistent to the Vallon Dol observations.

The advection of the western flow is also obvious on the water vapor content which indicates a higher concentration near Vallon Dol. Neither the temperature cooling nor the ozone increase is seen at Vallon Dol. The height of the ABL is usually taken as the level when the turbulent kinetic energy (TKE) reaches $5 \%$ of its surface value which gives $650 \mathrm{~m}$ at 14:00 UTC at Obs and $750 \mathrm{~m}$ at Vallon Dol. The so-called 'ABL' height of the model should reach $1100 \mathrm{~m}$ at 14:00, which corresponds to the boundary indicated by both lidar and radar (Fig. 14). We used comma since it is not, as we said before, a classical ABL top, but the top of the advected layer. To our opinion, the simulation underestimates this height. Moreover, the model (probably due to its $3 \mathrm{~km}$ resolution) does not seem to detect the $500 \mathrm{~m}$ UBL top. Nevertheless, the simulation shows that the vertical gradient of TKE is not homogeneous over Obs or Vallon Dol: turbulence is strong near the surface, sharply decreases at $200 \mathrm{~m}$ (300 m for the radar) and remains 


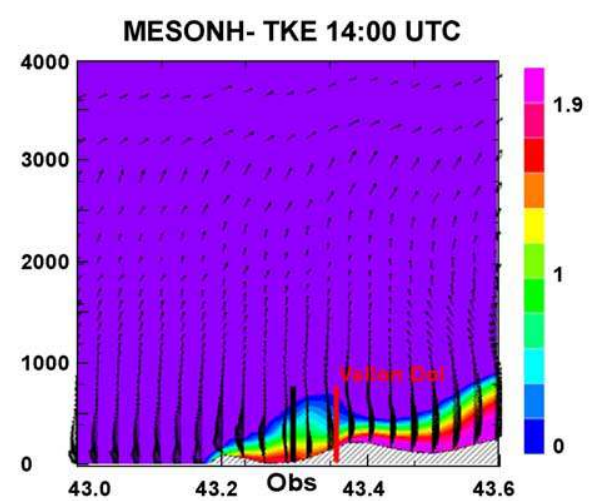

(a)

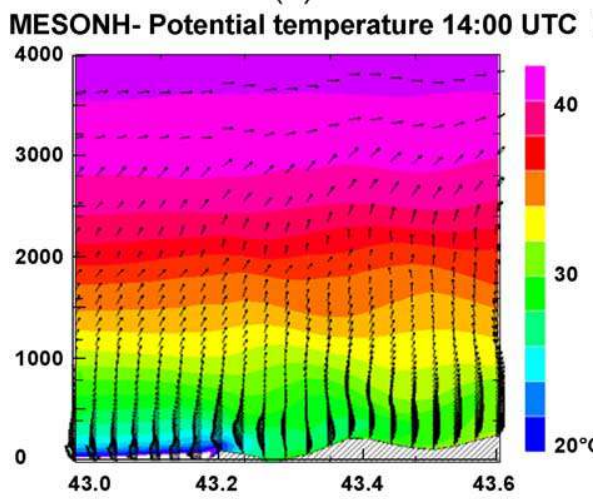

(c)

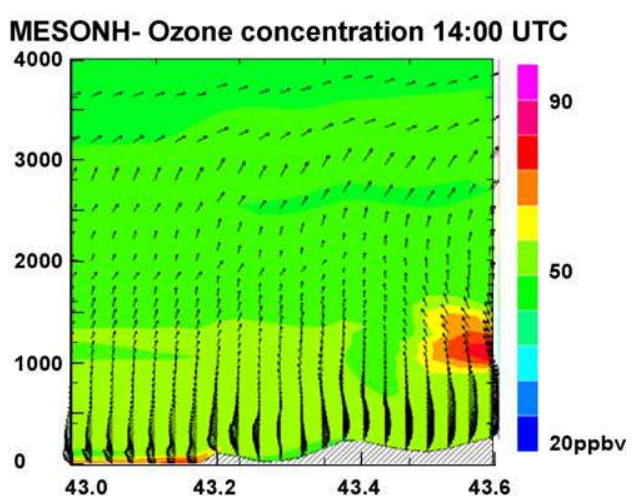

(b)

MESONH- Water vapor mixing ratio 14:00 UTC

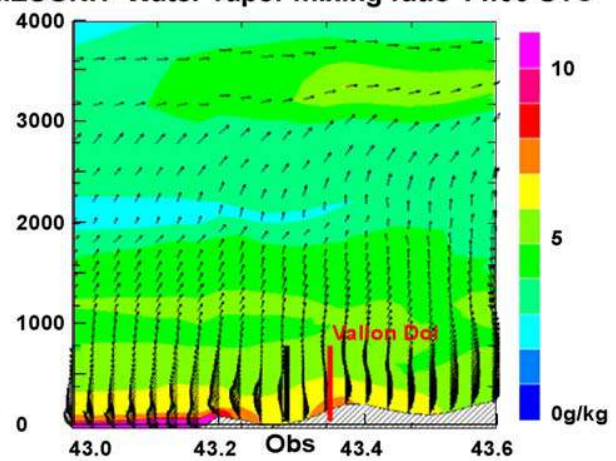

(d)

Fig. 17. Vertical cross-section from MesoNH-C simulation on June 26th at 14:00 UTC with (a) turbulent kinetic energy (TKE) $\left(\mathrm{m}^{2} \mathrm{~s}^{-2}\right)$, (b) ozone concentration (ppbv), (c) potential temperature $\left({ }^{\circ} \mathrm{C}\right)$ and (d) water vapor content $\left(\mathrm{g} \mathrm{kg}^{-1}\right)$. Black and red bars indicate respectively Obs and Vallon Dol locations.

active up to $650-750 \mathrm{~m}$, whereas to the North of the domain, it remains high on the whole ABL height (as in a classical ABL). This could be accounted to a sign of the existence of both superposed layers.

Finally, even if the simulations tend to confirm the complexity of the local features, the model does not retrieve the easterly flow obvious on the radar time-section at 14:00 (we checked it did not see it either, later in the afternoon). Once again the low resolution of the model has to be evoked, and particularly its inability to take into account the effect of the gap-flow to the East of Obs.

Back trajectories have been drawn to eventually detect a differential origin of the air masses at Obs and Vallon Dol at the lowest levels. Fig. 18 presents the horizontal back trajectories ending at Vallon Dol at 15:00 UTC at levels 300, 600, 800 and $1200 \mathrm{~m}$ : as expected, the western breeze is absolutely not seen at low level. The southern flow is well reproduced, which confirms that the model well takes into account the southern mesoscale sea breeze/synoptic flow. Fig. 19 compares the same back trajectories ending at Vallon Dol, to the one ending at Obs: the well-marked 


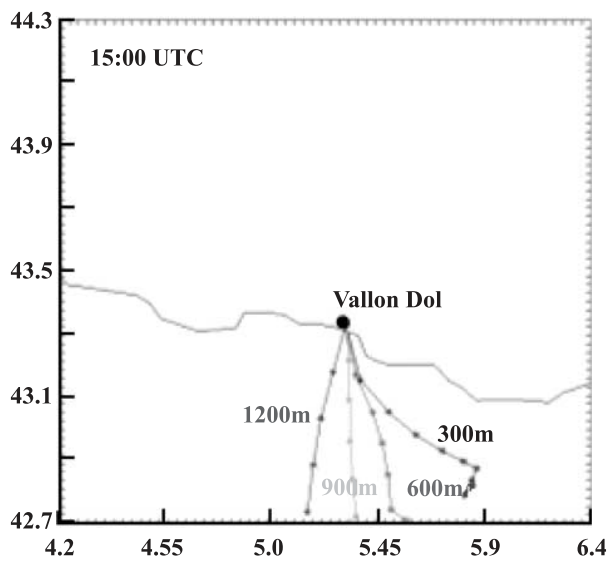

Fig. 18. Back trajectories ending at 15:00 UTC at Vallon Dol at various levels (300-600-900 and $1200 \mathrm{~m}$ ) from the MesoNH-C simulation on June 26th. The line coast is slightly wrong and Vallon Dol location should be northern.
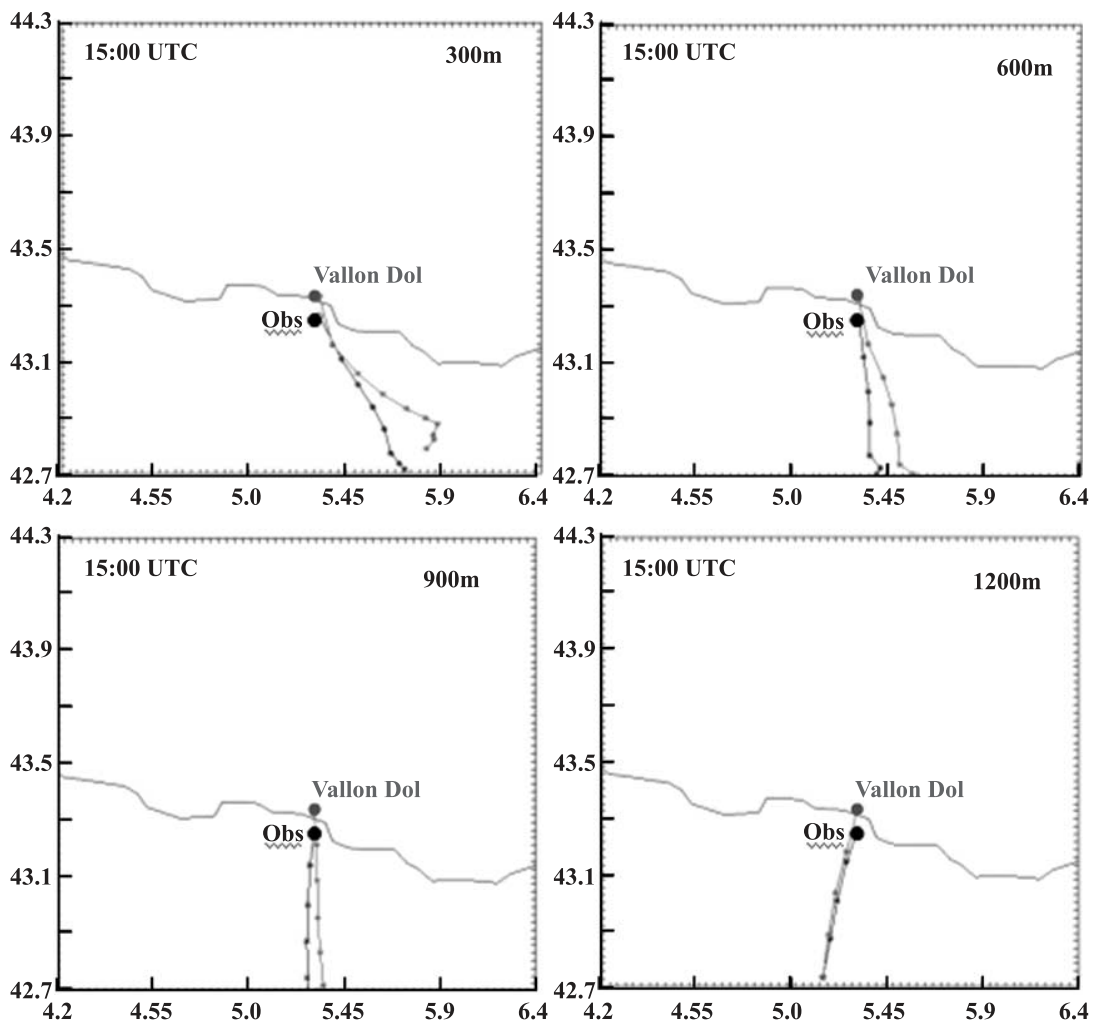

Fig. 19. Back trajectories ending at 300, 600, 900 and $1200 \mathrm{~m}$, at 15:00 UTC, at Observatoire or Vallon Dol. 
easterly flow blowing at Obs is not seen either as expected from the horizontal wind fields.

\section{Summary and conclusion}

The UV lidar signals and lidar extinction with the slope method have allowed the description of the stratification and its dynamics thanks to the quasi-continuous lidar measurements during the day. The ozone concentration revealed not to be a good indicator of the stratification in this situation. The continuous radar measurements have been compared with the lidar data and give results in a good agreement although the origin of the echoes of both systems is quite different.

The assembly set of many experimental instruments (lidar, UHF radar, sodar but also CVB ascent and radiosoundings for thermodynamics) enabled a coherent scheme to be proposed for the very complex dynamics and vertical stratification of June 26th. The simulation from the MesoNH-C model used with a 3-km mesh-grid helped for analysis and enabled the confirmation of:

- the co-existence of a western sea breeze below $500 \mathrm{~m}$ at Vallon Dol and a southern one in the southern ground stations around 12:00 UTC. The convergence of both breezes at Vallon Dol may induce an upward velocity in the lowest layers.

- the capping of these local breezes by a southern flow (extending to $800 \mathrm{~m}$ ) that is the composition of mesoscale sea breeze and synoptic flow.

- the heterogeneity of turbulence between the low UBL over Obs and Vallon Dol and the easterly advected layer.

However, the simulation did not allow the collapse of the Urban Boundary Layer in the afternoon to be distinguished from the advection of an eastern flow of very different thermodynamics. It must be noticed that pollution prediction in this complex area (proximity to the sea with an irregular coastline, large city, relief with local wind circulations) under weak wind conditions, is very hard and should be done at the highest resolution (probably with a large eddy simulation).

Moreover, the very complete set of experimental data showed consistency, with the entire data set being required for a thorough analysis, therefore, lidar or radar measurements have revealed insufficient if used alone in such a situation.

Finally we will conclude that the different processes affecting the ABL on the studied situation can be classified with increasing importance as follows: urban effect $\ll$ local sea breeze $<$ flow deflection due to relief and mesoscale sea breeze added to synoptic flow. This is going to be confirmed with the study of similar situations on other days of the ESCOMPTE experiment and opposed to situations with stronger winds.

\section{Acknowledgements}

We thank all the engineers, technicians and scientists who contributed to the success of ESCOMPTE as well as B. Cros and P. Durand who organized the campaign. We thank P. 
Mestayer (LMF, CNRS/ECN) for the coordination of the UBL side project. We also thank the numerous organizations involved in the ESCOMPTE financial support: the French Ministries of Research, National Development, and Environment, the Centre National de Recherche Scientifique/Institut National des Sciences de l'Univers (CNRS/INSU), the Agence De l'Environnement et de la Maîtrise de l'Energie (ADEME), Météo-France, the Centre National d'études Spatiales (CNES) and the Comité de Coordination Régional (CCR) of the air quality watch networks of the Provence-Côte d'Azur region.

\section{References}

Angevine, W.M., 1997. Errors in mean vertical velocities measured by boundary layer wind profilers. J. Atmos. Ocean. Technol. 14, 565-569.

Angevine, W.M., White, A.B., Avery, S.K., 1994. Boundary-layer depth and entrainment zone characterization with a boundary-layer profiler. Boundary-Layer Meteorol. 68, 375-385.

Campistron, B., Bénech, B., Dessens, J., Jacoby-Koaly, S., Dupont, E., Carissimo, B., 1997. Performance evaluation of a UHF boundary layer radar in raining conditions based on disdrometer measurements. 8th International Workshop on Technical and Scientific Aspects of MST Radar, Bangalore, India, pp. 334-337.

Carswell, A.I., 1983. Lidar measurements of the atmosphere. Can. J. Phys. 61, 378-395.

Chen, W., Kuze, H., Uchiyama, A., Suzuki, Y., Takeuchi, N., 2001. One-year observation of urban mixed layer characteristics at Tsukuba, Japan using a micro pulse lidar. Atmos. Environ. 35, 4273-4280.

Cousin, F., Tulet, P., Rosset, R., 2004. Interaction between local and regional pollution during Escompte 2001: impact on surface ozone concentrations (IOP2a and IOP2b). Atmos. Environ. 74, 117-137 (this issue).

Cros, B., Durand, P., Cachier, H., Drobinski, Ph., Fréjafon, E., Kottmeier, C., Perros, P.E., Peuch, V.-H., Ponche, J.-L., Robin, D., Saï, F., Toupance, G., Wortham, H., 2004. The ESCOMPTE program: an overview. Atmos. Res. 69, 241-279.

Dessens, J., Bénech, B., Campistron, B., Jacoby-Koaly, S., Dupont, E., Carissimo, B., 1997. A one year UHF validation campaign using rawinsondings, sodar, anemometers and disdrometer. 8th International Workshop on Technical and Scientific Aspects of MST Radar, Bangalore, India, pp. 200-203.

Frejafon, E., Sowinski, S., Allet, C., Ancellet, G., Durand, P., Gizard, E., Junkermann, W., Kalthoff, N., Robin, D., Said, F., 2002. QCQA of altitude ozone measurements during the ESCOMPTE campaign. 21st International Laser Radar Conference, Québec, Canada.

Jacoby-Koaly, S., Campistron, B., Bernard, S., Bénech, B., Girard, F., Dessens, J., Dupont, E., Carissimo, B., 2002. Turbulent dissipation rate in the boundary layer via UHF wind profiler Doppler spectral width measurement. Boundary-Layer Meteorol. 103, 361-389.

Kambezidis, H.D., Weidauer, D., Melas, D., Ulbricht, M., 1998. Air quality in the Athens basin during sea breeze and non sea breeze days using laser remote sensing technique. Atmos. Environ. 32, 2173-2182.

Klett, J.D., 1981. Stable analytical inversion solution for processing lidar returns. Appl. Opt. 20, $211-220$.

Kölsch, H.J., Rairoux, P., Wolf, J.P., Wöste, L., 1992. Comparative study of nitric oxide emission in the cities of Lyon, Geneva and Stuttgart using a mobile differential absorption lidar system. Appl. Phys., B 54, 89-94.

Lothon, M., Campistron, B., Jacoby-Koaly, S., Benech, B., Lohou, F., Girard-Ardhuin, F., 2002. Comparison of radar reflectivity and vertical velocity observed with a scannable C-band Doppler radar and two UHF profilers in the lower troposphere. J. Atmos. Ocean. Technol. 19, 899-910.

Menut, L., Flamant, C., Pelon, J., Flamant, P.H., 1999. Urban boundary-layer height determination from lidar measurements over the Paris area. Appl. Opt. 38, 945-954.

Mestayer, P., et al., 2004. The Urban Boundary Layer Field Experiment over Marseille UBL/CLU-ESCOMPTE: Experimental Set-up and First Results. Boundary-Layer Meteorol. (in press).

Ottersten, H., 1969. Atmospheric structure and radar backscattering in clear air. Radio Sci. 4, 1179-1193.

Puygrenier, V., Lohou, F., Campistron, B., Saï, F., Pigeon, G., Benech, B., Serça, D., 2004. Investigation on the fine structure of sea breeze during ESCOMPTE experiment. Atmos. Res. 74, 329-353 (this issue). 
Thomasson, A., Geffroy, S., Fréjafon, E., Weidauer, D., Fabian, R., Godet, Y., Nominé, N., Ménard, T., Rairoux, P., Moeller, D., Wolf, J.P., 2002. LIDAR mapping of ozone-episode dynamics in Paris and intercomparison with spot analysers. Appl. Phys., B 74, 453-459.

VDI-DIN 4210, 1997. VDI-DIN Handbuch Reinhaltung der Luft, Band 5. Beuth, Berlin.

Zanzottera, E., 1990. Differential absorption lidar techniques in the determination of trace pollutants and physical parameters of the atmosphere. Anal. Chem. 21, 279-319. 